\title{
Spatio-temporal downscaling of gridded crop model yield estimates based on
}

\section{machine learning}

3 C. Folberth ${ }^{a}$, A. Baklanov ${ }^{b, c}$, J. Balkovič ${ }^{a, d}$, R. Skalskýa,e, N. Khabarov ${ }^{a}$, M. Obersteiner ${ }^{a}$

$5 \quad{ }^{a}$ International Institute for Applied Systems Analysis, Ecosystem Services and Management Program, Schlossplatz

6 1, A-2361 Laxenburg, Austria, folberth@iiasa.ac.at, balkovic@iiasa.ac.at, skalsky@iiasa.ac.at,

7 khabarov@iiasa.ac.at, oberstei@iiasa.ac.at

$8 \quad{ }^{b}$ International Institute for Applied Systems Analysis, Advanced Systems Analysis Program, Schlossplatz 1, A-2361

9 Laxenburg, Austria, baklanov@iiasa.ac.at

$10{ }^{\mathrm{c}}$ National Research University Higher School of Economics, Soyuza Pechatnikov str., 16, St. Petersburg, Russian

11 Federation

$12{ }^{\mathrm{d}}$ Department of Soil Science, Faculty of Natural Sciences, Comenius University in Bratislava, Ilkovičova 6, 84215

13 Bratislava, Slovak Republic, balkovic@ fns.uniba.sk

$14{ }^{\mathrm{e}}$ National Agricultural and Food Centre, Soil Science and Conservation Research Institute, Trencianska 55, 82480

15 Bratislava, Slovak Republic, r.skalsky@vupop.sk

16

17 Corresponding author:

18 Christian Folberth

19 Schlossplatz 1

20 A-2361 Laxenburg, Austria

21 E-Mail address: folberth@iiasa.ac.at 


\section{Highlights:}

23 - Machine learning allows for highly accurate downscaling of GGCM outputs

24 - Increasing detail of climate features improves prediction accuracy

25 - Feature importance ranks in the order climate $\geq$ cultivar $>$ soil and topography

26 - Approach is scale-free and does not require prior assumptions on feature importance

27 It enables the development of robust downscaling tools with low user bias

28 


\section{Abstract}

30 Global gridded crop models (GGCMs) are essential tools for estimating agricultural crop yields

31 and externalities at large scales, typically at coarse spatial resolutions. Higher resolution

32 estimates are required for robust agricultural assessments at regional and local scales, where the

33 applicability of GGCMs is often limited by low data availability and high computational

34 demand. An approach to bridge this gap is the application of meta-models trained on GGCM

35 output data to covariates of high spatial resolution. In this study, we explore two machine

36 learning approaches - extreme gradient boosting and random forests - to develop meta-models

37 for the prediction of crop model outputs at fine spatial resolutions. Machine learning algorithms

38 are trained on global scale maize simulations of a GGCM and exemplary applied to the extent of

39 Mexico at a finer spatial resolution. Results show very high accuracy with $\mathrm{R}^{2}>0.96$ for

40 predictions of maize yields as well as the hydrologic externalities evapotranspiration and crop

41 available water with also low mean bias in all cases. While limited sets of covariates such as

42 annual climate data alone provide satisfactory results already, a comprehensive set of predictors

43 covering annual, growing season, and monthly climate data is required to obtain high

44 performance in reproducing climate-driven inter-annual crop yield variability. The findings

45 presented herein provide a first proof of concept that machine learning methods are highly

46 suitable for building crop meta-models for spatio-temporal downscaling and indicate potential

47 for further developments towards scalable crop model emulators.

48 Keywords: meta-model, extreme gradient boosting, random forests, maize yield, agricultural

49 externalities, climate features 


\section{Introduction}

In recent years, global gridded crop models (GGCMs) - combinations of a crop model

52 and global sets of gridded data - have become essential tools for estimating crop yields and

53 agricultural externalities under a wide range of environmental and management conditions (e.g.

54 Müller et al., 2017). Besides the direct provision and interpretation of model outputs for crop

55 yields alone (e.g. Rosenzweig et al., 2014) or their joint evaluation with externalities such as

56 crop water use (Liu et al., 2013; Elliott et al., 2014), GGCMs provide base layers of input data

57 for agro-economic or integrated assessment models (IAMs; Müller and Nelson, 2014) e.g. for

58 land use change analyses and optimization (e.g. Havlík et al., 2011).

The present global standard resolution of input data is $0.5^{\circ} \times 0.5^{\circ}$ corresponding to

60 approx. $50 \mathrm{~km} \times 50 \mathrm{~km}$ near the equator. This is foremost determined by climate data, which are

61 rarely available at higher resolutions at a global scale. Further common input data are

62 management information and in most cases soil data and topography (Müller et al., 2017). The

63 latter two are available at increasingly fine resolutions well below $1 \mathrm{~km}$ (Hengl et al., 2017a,

64 Jarvis et al., 2008), while management is typically reported at national or subnational

65 administrative levels (e.g. Sacks et al., 2010; Mueller et al., 2012). In few cases, simulations are

66 run at the sub-grid level accounting for some heterogeneity in soil and topography (Skalský et

67 al., 2008; Balkovič et al., 2014). Regardless of the spatial resolution, each simulation unit is

68 treated as a homogenous field in the crop model.

While this spatial resolution provides sufficient detail for robust assessments at macro

70 scales such as the country level, there is increasing concern that GGCM estimates and hence

71 impact assessments at coarse resolutions often miss actual on-ground conditions. As only 
72 average or dominant characteristics present within each grid are considered for simulations,

73 assumptions and data may not match actually farmed land (e.g. Folberth et al., 2016) and

74 farming practices (e.g. Reidsma et al., 2009). In addition, they may omit farm-level

75 heterogeneity present at the sub-grid level (Ewert et al., 2011), which is essential for local to

76 regional decision-making and stakeholder information (Rosenzweig et al., 2018).

Applying gridded crop models at very high spatial resolutions on the other hand increases

78 computational demand substantially and is often limited by data availability as outlined above.

79 Foremost climate data at suitable temporal resolutions for crop models - which is typically a

80 daily time step (Müller et al., 2017) - are hardly available at fine spatial resolutions. The

81 presently highest resolving global daily dataset known to the authors has $0.25^{\circ} \times 0.25^{\circ}$ (Ruane et

82 al., 2015), while regional products may have resolutions of up to $0.11^{\circ} \times 0.11^{\circ}$ (Haylock et al.,

83 2008). Temporally coarser data e.g. with a monthly time step, however, are available at very fine

84 resolutions up to <1 km (e.g. Wang et al., 2016; Fick and Hijmans, 2017).

85 An approach lending itself to address these issues in an efficient and flexible way is the

86 use of meta-models built from coarser GGCM simulations. This allows for deriving estimates of

87 crop yields and associated agricultural externalities at high, virtually scale-free, spatial

88 resolutions without requirements for setting up high-resolution crop model infrastructures

89 including their comprehensive data requirements. There is no scientific literature on crop meta-

90 model development for spatio-temporal predictions across scales known to the authors. The

91 potentially most closely related field is the recently evolving crop model emulator development

92 at the grid cell level. Examples are the development of regressions along climate change

93 trajectories as such (e.g. Blanc and Sultan, 2015; Blanc, 2017) or the use of global crop model 
94 simulations with artificial alterations of climate variables to retrieve estimates of climate change

95 impacts for assessment studies based on regressions along temperature, precipitation, and $\mathrm{CO}_{2}$

96 concentrations (Ruane et al., 2017; Rosenzweig et al., 2018). The production of high-resolution

97 crop yield surfaces in contrast is foremost accomplished using simplified crop model algorithms

98 (e.g. IIASA/FAO, 2012) or purely statistical approaches (e.g. Mueller et al., 2012). Common to

99 all referenced approaches is that they (a) are based on narrow sets of a priori selected covariates

100 based on modelers' assumptions and (b) do not allow for or have not been tested for the joint

101 evaluation of agricultural productivity and externalities. Crop model emulators are in addition

102 typically parameterized at the grid level, which renders them spatially determined and scale-

103 depended.

104 The presently most flexible approaches for data-driven development of models with high 105 accuracy can be found in the field of machine learning. Machine learning is a collective term for 106 a wide range of data analysis and data-driven forecasting techniques. The most advanced

107 techniques are characterized by the ability to digest large amounts of covariates (herein syn.

108 features, syn. predictors) to provide predictions for both numeric and categorical variables with

109 algorithms of high complexity and flexibility, which determine the relevance of provided

110 covariates themselves (e.g. Witten et al., 2016). Examples of methodologic approaches are

111 neural networks, various forms and derivatives of regression trees, as well as clustering

112 techniques. While simpler methods such as multiple linear or lasso regressions are typically

113 computationally faster and straightforward to interpret, they show typically a substantially lower

114 performance. Within agricultural sciences, applications are to date mostly limited to processing

115 and analyzes of remote sensing data (e.g. Duro et al., 2012; Ali et al., 2015). Few exceptions are 
116 the development of crop nutrient response models for studying yield responses in sub-Saharan

117 Africa based on field trial data (Hengl et al., 2017b) and the use of data mining tools for

118 identifying crop growth limitations (Delerce et al., 2016).

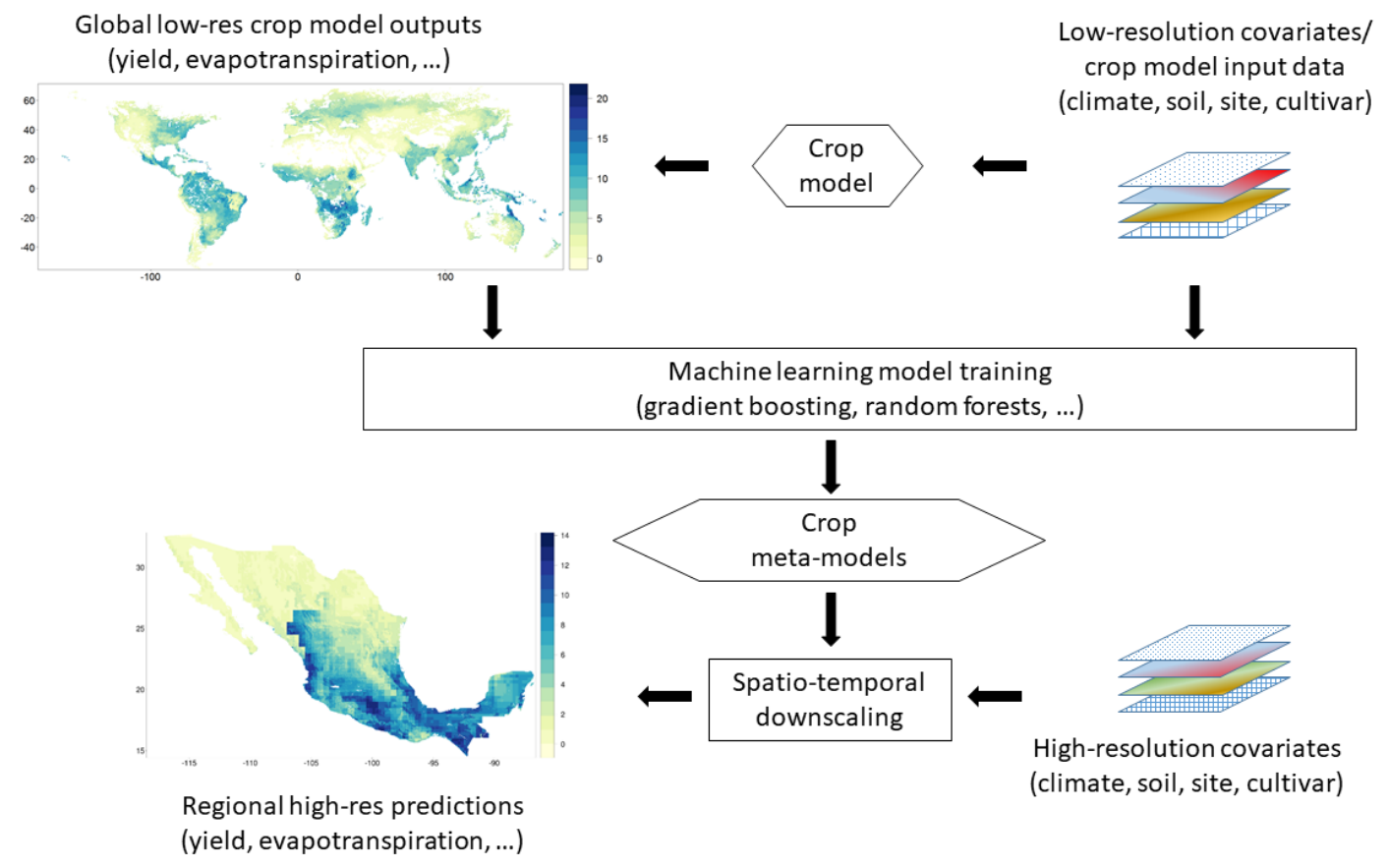

121 Figure 1. Schematic representation of the downscaling approach presented in this study. estimates of corresponding variables at a higher spatial resolution.

In this study, we evaluate machine learning as an approach for building crop meta-

126 models. The focus is on the feasibility to use low-resolution global crop simulations of maize

127 yield potential for predictions at a high resolution, here exemplary the extent of Mexico, as 
128 depicted schematically in Figure 1. Non-nutrient and pest limited yield potentials (Lobell et al.,

129 2009) with and without sufficient water supply were selected as a target variable as they allow

130 for a thorough evaluation of climate-related covariates without inference from soil nutrient

131 trajectories. Two of the presently most flexible and in recent competitions best performing

132 (Fernández-Delgado, 2014; Chen and Guestrin, 2016) machine learning approaches for numeric

133 predictions, extreme gradient boosting and random forests, are tested and compared against crop

134 model simulations carried out at the finer resolution. Objectives of the study are to (a) evaluate

135 the meta-model performance in downscaling the low-resolution global yield simulation to high-

136 resolution predictions in the study region of Mexico, (b) identify most important covariates

137 required by the meta-model, and (c) test the approach for predictions of selected agricultural

138 externalities across scales. To provide an exemplary application case, machine learning model

139 predictions are performed at a very high spatial resolution $(1 \mathrm{~km} \times 1 \mathrm{~km})$ in major producing

140 areas and benchmarked against reported inter-annual yield variability, a key performance

141 indicator for climate change impact assessments (Müller et al., 2017). Finally, an outlook

142 provides suggestions for further steps to extend the models' capabilities.

\section{Methods and Data}

$144 \quad 2.1$ Gridded crop model description

145 Crop simulations were carried out using a gridded version of the Environmental Policy

146 Integrated Climate model (EPIC). EPIC was initially developed to assess the impacts of

147 management on crop yields (Williams, 1995). It has constantly been updated to cover additional

148 processes such as effects of elevated atmospheric $\mathrm{CO}_{2}$ concentration on plant growth (Stockle et 
149 al., 1992), detailed soil organic matter cycling (Izaurralde et al., 2006, Izaurralde et al., 2012),

150 and an extended number of crop types and cultivars (e.g. Kiniry et al., 1995; Gaiser et al., 2010)

151 among others (see Gassman, 2004). More details of the crop growth model are provided in

152 Supplementary Text S1.

153 The gridded version of EPIC used here, EPIC-IIASA (Balkovič et al., 2014), runs the

154 EPIC model for a given set of simulation units derived from intersecting homogenous response

155 units (soil and topography), administrative borders, and climate grids (Skalský et al., 2008).

156 Thereby, each simulation unit is treated as a representative, homogenous field.

1572.2 Study regions, delineation of simulation units, and simulation period

158 Simulations and meta-model predictions were performed (a) at the global scale at a

159 coarse spatial resolution and (b) for Mexico at a finer resolution. The latter was selected as an

160 exemplary study region as it encompasses the three major climates tropic, temperate, and (semi-

161 )arid and has a large coverage of maize harvest areas. The basic spatial resolutions at the two

162 scales were grids of 5' (global) and $0.5^{\prime}$ (Mexico), respectively, serving also as basic references

163 for spatial harmonization of all underlying input data (topography, soil, and land cover).

164 Individual pixels were aggregated to homogeneous response units (HRUs) based on slope,

165 altitude and soil classes. HRU provide aggregated spatial units which are expected to be

166 homogenous in their bio-physical response and relatively stable over time. The basic bio-

167 physical drivers assumed for an HRU are hardly adjustable by farmers, which allows for

168 analyzing impacts of the same management practices employed across a variety of natural

169 conditions. Intersecting HRUs with administrative units (countries globally and states for 
170 Mexico) and the climate grids of $0.5^{\circ} \times 0.5^{\circ}$ and $0.25^{\circ} \times 0.25^{\circ}$ resolution at the global and

171 Mexican scale, respectively, resulted in final simulation units with a total number of $1.3 \times 10^{5}$

172 globally and $2.3 \times 10^{5}$ for Mexico. Spatially explicit inputs for EPIC on topography and soil were

173 then calculated as mean (altitude) or majority (slope, soil) values across all pixels within the

174 simulation unit. Additional evaluations were carried out for the Mexican state of Jalisco, which is

175 the top rainfed maize producing state in the country according to Servicio the Información

176 Agroalimentaria y Pesquera (SIAP, 2018b).

Simulations were performed for the years 1980-2010 based on climate data coverage

178 (Section 2.3.1) and evaluated for the period 1990-2009 as the crop model equilibrates during the

179 first simulation years and the global simulations used for training machine learning models did

180 not provide outputs for the year 2010 in regions with growing seasons crossing years.

1812.3 Crop model input data

$182 \quad$ 2.3.1 Climate data

183 Gridded climate data were obtained from the publicly available AgMERRA climate

184 dataset (Ruane et al., 2015) at spatial resolutions of $0.5^{\circ} \times 0.5^{\circ}$ for global simulations and

185 predictions and $0.25^{\circ} \times 0.25^{\circ}$ for the study region of Mexico. AgMERRA covers the period

186 1980-2010 and combines data from the Modern-Era Retrospective Analysis for Research and

187 Applications (MERRA; Rienecker et al., 2011), station data, and remotely sensed datasets and

188 has been bias corrected using stations from agricultural land only. The high-resolution version

189 was obtained from the providers' website directly, the coarser resolution was provided through

190 the Global Gridded Crop Model Intercomparison (GGCMI) project (Elliott et al., 2015). 
191 Although higher resolution monthly climate data would be available for the study region (e.g.

192 Wang et al., 2016) allowing for higher resolution meta-model predictions, these would not allow 193 for benchmarking against EPIC simulations requiring daily climate data.

$194 \quad 2.3 .2$ Soil data

Soil data were retrieved from the Harmonized World Soil Database v1.2 (HWSD;

196 FAO/IIASA/ISRIC/ISS-CAS/JRC, 2012) at both spatial scales. For each grid cell at 5' (global)

197 or $0.5^{\prime}$ (Mexico) resolution, the dominant soil type of the largest soil mapping unit was selected

198 as the representative soil type. Soil characteristics considered in EPIC and the machine learning

199 approaches are depth, texture, coarse fragment content, bulk density, soil organic carbon content,

$200 \mathrm{pH}$, electric conductivity, cation exchange capacity, base saturation, and carbonate content

201 (Table 1).

$202 \quad 2.3 .3$ Topography

203 For the global setup, elevation data were adopted from GTOPO30 (USGS, 2002)

204 calculating the mean elevation in each simulation unit. Slope classes were obtained from the

205 Global Agro-ecological Zones Assessment for Agriculture (GAEZ; Fischer et al., 2012). For the

206 high-resolution setup constructed for Mexico, both elevation and slopes were derived from the

207 SRTM 4.1 database provided by CIAT-CSI (Jarvis et al., 2008).

$208 \quad 2.3 .4 \quad$ Land use

209 Global low-resolution simulations were carried out for all simulation units presently

210 containing cropland according to at least one of the datasets Global Land Cover 2000 database 
211 (Global Land Cover 2000 database, 2003) or SPAM (You et al., 2017). For Mexico, simulations

212 were done for all simulation units and MIRCA2000 was used for identifying simulation units

213 containing relevant maize harvest area, here defined as $>5 \%$ of total area. Selected analyses were

214 restricted to these in order to evaluate model performance for the whole land and relevant

215 cropland only.

\section{$216 \quad 2.3 .5 \quad$ Crop management}

217 Maize was used as a model crop due to its extensive cultivation globally and in Mexico.

218 Default crop parameters from the EPIC model were used, which reflect a high-yielding variety

219 adapted to warm climate (Kiniry et al., 1995). Crop growing seasons were adopted at both scales

220 from Sacks et al. (2010) as provided by Elliott et al. (2015). PHU were calculated from planting

221 to harvest using long-term monthly climate data for the whole time-period covered by the

222 AgMERRA climate dataset (1980-2010) at each spatial resolution separately.

223 To obtain non-nutrient limited maize yield potentials (Lobell et al., 2009), mineral N

224 fertilizer was applied automatically by the EPIC model based on plant stress to avoid plant

225 growth limitations due to nutrient deficits, which may cause trends in yields over time due to

226 nutrient mining. The maximum applied amount of fertilizer was set to $500 \mathrm{~kg} \mathrm{~N} \mathrm{ha}^{-1} \mathrm{yr}^{-1}$, which

227 is commonly more than sufficient for maximizing maize yields (e.g. Folberth et al., 2013).

228 Simulations were carried out with water supply either from precipitation only (rainfed) or with

229 sufficient supplementary irrigation water supply (fully irrigated). Irrigation water was applied

230 based on plant stress analogously to fertilizer with an annual maximum volume of $2000 \mathrm{~mm}$. 
231 Other management practices were kept at a basic level with four operations in each season: field 232 cultivation, planting, harvest, and stover removal.

\subsection{Machine learning framework}

We test two state-of-the-art tree-based ensemble methods, extreme gradient boosting and 235 random forests. Ensemble methods employ a collection of learning algorithms to achieve better

236 predictive power than could be gained from any of these algorithms alone. For ensembles such as

237 extreme gradient boosting and random forests, it is typical to use trees as building blocks to

238 allow for invariance to scaling of inputs and complex interactions between features. Since

239 ensembles have additional parameters responsible for aggregation of learning algorithms, they

240 have more flexibility in fitting training data than single-algorithm approaches do. Thus,

241 ensembles are more prone to overfitting. Overfitting is prevented through out-of-bag error

242 monitoring, n-fold cross-validation, correction of the ensemble by regularization that makes the

243 training procedure more conservative, and testing on the holdout dataset covering $25 \%$ of

244 observations (see below). Both extreme gradient boosting and random forests are insensitive to

245 multiple correlation of covariates with respect to prediction accuracy and overfitting. The

246 quantification of variable importance, however, may be affected if covariates are strongly

247 correlated (see Section 2.4.3).

Crop model simulation data (serving here as observations) for building machine learning

249 models was randomly split into training and validation sets containing $75 \%$ and $25 \%$ of samples,

250 respectively, which is a common split ratio in machine learning. About $19.5 \times 10^{5}$ samples

251 (simulation units $\mathrm{x}$ simulation years) were used for model training and $6.5 \times 10^{5}$ for validation. 
252 Machine learning models were built separately for the two water management scenarios, rainfed

253 or sufficiently irrigated, within the statistical computing software R (R Development Core Team,

254 2008) using the packages specified in the following sections.

255 To streamline the presentation of results, the main body of the paper focuses on results

256 from extreme gradient boosting. The evaluation of the random forests models is presented in the

257 SI and discussed within the main body where relevant.

\section{$258 \quad 2.4 .1 \quad$ Extreme gradient boosting}

259 Similar to other boosting methods, extreme gradient boosting is an ensemble learning

260 technique that sequentially builds the model: each tree is fit on a modified version of the original

261 training data set. I.e., every new tree uses information from previously grown trees. This is the

262 key difference to random forests (see below). Extreme gradient boosting generalizes boosting

263 methods by allowing minimization of an arbitrary differentiable loss function. In this study, we

264 employed the R package XGBoost for extreme gradient boosting, a highly efficient realization of

265 the gradient boosting approach that showed the best performance in recent machine learning

266 challenges (Chen and Guestrin, 2016). Being a learning algorithm with high flexibility, extreme

267 gradient boosting is prone to overfitting, especially, if training data are scarce, which is not the

268 case here. Typically, parameter tuning is done by performing an exhaustive grid search along

269 parameter dimensions using the default parameters as the reference point. This was here not

270 considered meaningful due to the vast amount of training data, rendering a full grid search

271 computationally inefficient and unneeded, due to extremely low error obtained already in a

272 limited grid search. I.e., we tuned only key parameters for shrinkage and learning (eta, 
273 max_depth, nrounds; Table S1). In our case, the default parameter values resulted in stable but

274 improvable performance with $\mathrm{R}^{2}=0.94$ for the test dataset. This suggested to increase the

275 maximum tree depth and local variation of the learning rate (eta). The grid search resulted in

$276 \mathrm{R}^{2}=0.99$ for both training and test data with eta=0.15 or 0.30 and max_depth $=15$ or 20 . The

277 lowest RMSE in both training and test data was obtained with eta=0.15 and max_depth=20 in a

278 five-fold cross validation (Table S2). Although this parameter set results in a marginal overfit, it

279 also showed the best performance in regression metrics and mean absolute error (MAE; not

280 shown), the main performance indicators used herein (see section 2.5.1). It was hence selected

281 for performing the predictions. Extending the grid search to by increasing the rounds of tree

282 building (nrounds) from 60 to 100 provided only a negligible increase in performance (Table

283 S2). Resulting parameters were hence eta $=0.15$, max_depth $=20$, and - to ensure very high

284 accuracy - nrounds $=100$.

285 Since extreme gradient boosting may produce negative predictions even if the training

286 data does not have them, the lower boundary was set to zero and all predictions below corrected

287 to this value. This was the case for rainfed crop yields in $0.1 \%$ of samples with predictions of up

288 to $-0.19 \mathrm{t} \mathrm{ha}^{-1}$ in the validation set and $0.02 \%$ of the predictions for Mexico with up to $-0.08 \mathrm{tha}^{-}$

289 . Irrigated crop yield predictions were affected in the validation set only with up to $-0.09 \mathrm{t} \mathrm{ha}^{-1}$ in

$290<0.01 \%$ of samples.

$291 \quad 2.4 .2$ Random forests

292 In contrast to boosting methods, tree ensembles build a number of models in parallel

293 from which average predictions are derived. Bagging is a basic approach to introduce an 
294 ensemble that consists of a number of decision trees trained on random subsets of data

295 (bootstrapped training samples). Random forests (Breiman, 2001) employ not only bagging (row

296 sub-sampling) but also column sub-sampling, i.e., every time a split in a tree is examined for a

297 random subset of candidate features drawn from the full set of features. This effectively de-

298 correlates the trees. As reported in a recent meta-study of machine learning algorithms

299 (Fernández-Delgado, 2014), random forests was identified as the best family of classifiers. In

300 this study, random forests models were constructed using the R package h2o, which serves as a

301 link to the H2O.ai machine learning cluster environment (The H2O.ai team, 2017).

302 As random forests are less prone to overfitting, global parameters were tuned to achieve a

303 reasonable balance between performance and computational demand, which increases linearly

304 with number of trees and tree depth. Major parameters to adjust in random forest are number of

305 trees (ntrees), maximum tree depth (max_depth), and a number of features considered for each

306 split decision (mtries). The latter is per default one third of total features for numeric predictions.

307 Starting from the default values ntree $=50, \max \_$depth $=20$, and mtries $=[\text { number of features }]^{*} 0.3$,

308 we found an increase in performance in terms of regression coefficients and MAE of the test

309 dataset up to max_depth=30 with negligible improvements if ntree was increased from 50 to 80

310 (Figure S1). Further increasing the parameter values provides a marginal increase, but would not

311 justify the increase in computational demand, which is already at any point substantially higher

312 than for extreme gradient boosting (see also section 4.4). Increasing or decreasing the parameter

313 mtries from about $33 \%$ of feature number as a default to $20 \%$ or $50 \%$ affected model

314 performance only marginally as well with no changes in $\mathrm{R}^{2}$ or slope and changes by $\pm 0.01 \mathrm{tha}$

315 in intercept and MAE. 
Both methods determine feature importance internally. To obtain an overall summary of

318 the importance of predictors, the residual sum of squares (for regression) or the Gini index (for

319 classification; Breiman et al. 1984) are used. For ensembles of regression trees, the total amount

320 by which the residual sum of squares is decreased by splits over a fixed feature is calculated and

321 then average over all trees. Larger values point to predictors that are more important. Likewise,

322 in the case of ensembles of classification trees, the total amount that the Gini index is reduced

323 due to splits is cumulated over a given feature and averaged over all trees. For both machine

324 learning methods, we present the relative importance of each feature as percentage. Due to

325 differences in the estimation of feature importance, it is not feasible to compare importance

326 across different algorithms quantitatively. In addition, multiple correlated features, which can be

327 expected here at least among soil characteristics or (monthly) climate variables, are known to

328 bias the quantification of feature importance (Toloşi and Lengauer, 2011). E.g., if two features

329 included in an extreme gradient boosting model are perfectly correlated, each of them will

330 receive $50 \%$ of the actual importance. For these reasons, we focus in the evaluation of feature

331 importance foremost on the ranking of features rather than their quantitative contributions.

$332 \quad$ 2.4.4 Machine learning features and feature engineering

333 Table 1. Features and target variables used in machine learning experiments. Several statistics 334 were calculated for each climate variable VAR in the first section of the table as listed in 335 the second section. Averages were calculated for the temperature indices TMX and TMN, 336 sums for all others. Total number of features is 247 , the maximum number used in model 

to the temporal dimension.

\begin{tabular}{|c|c|}
\hline Abbreviation & Variable description \\
\hline \multicolumn{2}{|r|}{ Climate variables (VARs; transient) } \\
\hline TMX & Maximum temperature $\left[{ }^{\circ} \mathrm{C}\right]$ \\
\hline TMN & Minimum temperature $\left[{ }^{\circ} \mathrm{C}\right]$ \\
\hline GDD & Growing degree days $\left[{ }^{\circ} \mathrm{C}\right]$ \\
\hline RAD & Solar radiation $\left[\mathrm{MJ} \mathrm{m}^{-2}\right]$ \\
\hline PET & Potential evapotranspiration [mm] \\
\hline PRCP & Total precipitation $[\mathrm{mm}]$ \\
\hline WET & Wet day frequency [d] \\
\hline CMD & Climatic moisture deficit (PRCP-PET) [mm] \\
\hline \multicolumn{2}{|r|}{ Temporal aggregates and derivatives of climate variables (transient) } \\
\hline$V A R \_\mathrm{X}$ & Monthly value for month $\mathrm{X}\{1: 12\}$ since planting (e.g. "TMX_1") \\
\hline VARsd_X & Standard deviation of mean value in month X $\{1: 12\}$ (e.g. "TMXsd_1") \\
\hline VARavYRcal & Average of climate variable in calendar year (January to December) \\
\hline VARsumYRcal & Sum of climate variable in calendar year (January to December) \\
\hline VARavYRgs & Average of climate variable in growing season year (12 months from planting) \\
\hline VARsumYRgs & Sum of climate variable in growing season year (12 months from planting) \\
\hline VARskYRgs & Skew of climate variable in growing season year (12 months from planting) \\
\hline VARavGS & Average of climate variable in growing season (planting month to harvest) \\
\hline VARsumGS & Sum of climate variable in growing season (planting month to harvest) \\
\hline VARskGS & Skew of climate variable in growing season (planting month to harvest) \\
\hline \multicolumn{2}{|r|}{ Soil and site variables (static) } \\
\hline DEPTH & Total soil depth [m] \\
\hline SAND & Sand content in topsoil [\%] \\
\hline CLAY & Clay content in topsoil [\%] \\
\hline PH & $\mathrm{pH}$ in topsoil [-] \\
\hline SB & Sum of bases in topsoil $\left[\mathrm{cmol} \mathrm{kg}^{-1}\right]$ \\
\hline CEC & Cation exchange capacity in topsoil $\left[\mathrm{cmol} \mathrm{kg}^{-1}\right]$ \\
\hline EC & 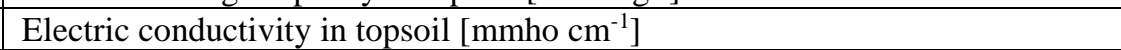 \\
\hline ROK & Coarse fragment (rock) content in topsoil [\%] \\
\hline BD & Bulk density in topsoil $\left[\mathrm{g} \mathrm{cm}^{-3}\right]$ \\
\hline CARB & Carbonate content in topsoil [\%] \\
\hline $\mathrm{OC}$ & Organic carbon content in topsoil [\%] \\
\hline PAW & Total plant available water capacity $\left[\mathrm{m}^{3} \mathrm{~m}^{-3}\right]$ \\
\hline HG & Soil hydrologic group (water infiltration potential) [-] \\
\hline SLP & Hill slope [\%] \\
\hline \multicolumn{2}{|r|}{ Cultivar and growing season variables (static) } \\
\hline PHU & Potential heat units/growing degree days from planting to maturity $\left[{ }^{\circ} \mathrm{C}\right]$ \\
\hline LVP & Length of vegetation period. Average days from planting to maturity [d] \\
\hline \multicolumn{2}{|r|}{ Target variables (transient) } \\
\hline YLDG & Maize crop yield [t ha' $\left.{ }^{-1}\right]$ \\
\hline CAW & Crop available water $[\mathrm{mm}]$ \\
\hline GSET & Growing season evapotranspiration $[\mathrm{mm}]$ \\
\hline
\end{tabular}


Features are based on crop model input data, i.e. soil, climate and management

341 specifications as described in Section 2.3. Daily climate data were in a first step aggregated to

342 monthly sums or averages depending on the variable. For each simulation unit, the month of

343 planting was designated as month 1 to harmonize the order of months from planting globally.

344 Subsequently, annual and growing season values were calculated for (a) the growing season

345 months (based on the static length of reported vegetation period (LVP)), (b) the calendar year,

346 and (c) a year starting from the planting month (Table 1). This process is referred to as feature

347 engineering, i.e. the specification of model features beyond raw data based on expert knowledge.

348 Soil variables were foremost adopted for the topsoil, which has the largest impact on crop

349 growth. Only variables with high importance for water availability, depth, plant available water

350 capacity (PAW; difference of water contents at field capacity and wilting point), and hydrologic

351 soil group $(\mathrm{HG})$ refer to the whole soil profile. Additional characteristics considered potentially

352 relevant for the meta-models were hill slope as a site characteristic and PHU and LVP as cultivar

353 characteristics.

Models were built for three target variables: maize crop yield (yield hereafter), growing

355 season ET (GSET), and crop available water (CAW). The latter is a balance of initial soil

356 humidity at the beginning of the growing season, growing season precipitation and irrigation

357 water if provided, surface runoff, and percolate.

358 To evaluate the importance of raw and engineered climate features, the machine learning

359 models were trained with various feature subsets (Table 2). Soil and site data, PHU, and LVP

360 were considered in all scenarios to evaluate the importance of climate variables only. Annual

361 climate data can be considered the most general feature set. Growing season climate considers 
362 the mean or sum of climatic conditions experienced by the crop. Monthly data in turn account for

363 intra-seasonal variability and climate effects in certain growth stages. The complete climate

364 feature set takes all aspects into account and solely lets the algorithm select the most relevant

365 features. Thereby, months beyond the sixth from planting were excluded to keep the number of

366 features at a reasonable extent, considering that maize cultivars hardly require $>180$ days to

367 reach maturity.

368 Table 2. Climate feature subsets used in the analyses. Besides indicated climate features (see

369 Table 1 for details), soil and site data, PHU, and LVP were considered in all training sets.

\begin{tabular}{|l|l|l|}
\hline Feature subset & Climate features considered & Number of features \\
\hline annual climate & VARavYRcal, VARsumYRcal & 23 \\
\hline growing season climate & VARavGS, VARsumGS & 23 \\
\hline monthly climate & $V A R \_X($ with $\mathrm{X} \leq 6)$ & 63 \\
\hline complete climate & all features except $V A R \_X$ with $\mathrm{x} \geq 7$ & 151 \\
\hline
\end{tabular}

3712.5 Performance metrics and model evaluation

372 2.5.1 Machine learning model performance compared to crop model simulations

374 against the validation subset of global EPIC simulations and (b) downscaling predictions against

375 the high-resolution benchmark simulations for Mexico. Mean absolute error (MAE) was used as

376 a metric for mean model bias. Nash-Sutcliffe efficiency (NSE) was used as an indicator for the

377 accuracy of inter-annual yield variability.

378 The coefficient of determination $\mathrm{R}^{2}$ was calculated according to 
$379 \quad R^{2}=1-\frac{\sum_{i=1}^{n}\left(Y_{\text {ref }, i}-\hat{Y}_{\text {red }}\right)^{2}}{\sum_{i=1}^{n}\left(Y_{\text {ref }, i}-\bar{Y}_{\text {ref }}\right)^{2}}$

380 where $i$ is the number of the sample point (one simulation year-location) considered, $n$ is

381 the total number of sample points across simulation units and years, $Y_{\text {ref }}$ is the reference crop

382 yield, $\hat{Y}_{\text {pred }}$ is the fitted yield, and $\bar{Y}_{\text {ref }}$ is the arithmetic mean of reference samples.

$383 \quad$ MAE was calculated as

$384 \quad M A E=\frac{\sum_{i=1}^{n}\left|Y_{\text {pred }, i}-Y_{\text {ref }, i}\right|}{n}$

385 where $Y_{\text {pred,i } i}$ is the machine learning model predicted value for data point $i$ and $Y_{r e f, i}$ is the 386 corresponding EPIC simulated reference value.

387 NSE is a common metric for model performance over time, used especially in hydrology

388 (Nash and Sutcliffe, 1970). It is calculated using the same variables as the prior metrics but

389 separately for each simulation unit over time according to

$390 \quad N S E=1-\frac{\sum_{t=1}^{m}\left(Y_{r e f, t}-Y_{\text {pred }, t}\right)^{2}}{\sum_{t=1}^{m}\left(Y_{\text {ref }, t}-\bar{Y}_{\text {ref }}\right)^{2}}$

391 where $Y_{\text {pred,t } t}$ is the yield estimated by the meta model for year $t$ and $Y_{\text {ref, } t}$ the

392 corresponding reference. NSE can range from $-\infty$ to +1 with NSE $>0$ indicating that model

393 predictions are more useful than the mean of reference data. As NSE is sensitive to both absolute

394 values and their temporal dynamics, it was in addition calculated for zero-centered yield values

395 (sample mean removed) in order to assess inter-annual yield variability alone, which is

396 considered a vital GGCM evaluation characteristic for climate (change) impact assessments (e.g.

397 Müller et al., 2017). 
Evaluations were partly carried out at the level of major Koeppen-Geiger climate regions

399 (Figure S2) following the rules of Peel et al. (2007). Koeppen-Geiger regions were identified for 400 each $0.25^{\circ} \times 0.25^{\circ}$ climate grid for the 31-year climatology of the AgMERRA dataset 19804012010.

2.5.2 Model performance compared to regional statistics

The EPIC model itself and the global gridded EPIC-IIASA framework have been

404 evaluated and validated thoroughly at various scales from the agricultural plot (Kiniry et al.,

405 1995; Gassmann et al., 2004; Izaurralde et al., 2006) to regional (Gaiser et al., 2010; Folberth et

406 al., 2012) and global assessments (Balkovič et al., 2014; Müller et al., 2017) finding good

407 agreement with reported yields. Here we provide a brief evaluation of model performance in

408 terms of inter-annual yield variability expressed as NSE (eq. (3)) for the top ten maize producing

409 municipios (second-level administrative units) of the major maize producing state Jalisco, where

410 crop management can be considered fairly stable and data quality reasonable. This also illustrates

411 an exemplary application of the machine learning framework. Reported maize yields were

412 obtained from SIAP (2018a). Crop yields are reported since the year 2003 at the second

413 administrative level, resulting in an evaluation period from 2003-2009 considering the time

414 period for crop model simulations (see Section 2.2). Besides the machine learning predictions

415 corresponding to the high-resolution input data for the crop simulations at the scale of Mexico

416 (see Section 2.3.1), predictions were also produced using monthly climate surfaces from

417 ClimateNA 5.60 (Wang et al., 2016) at a spatial resolution of $1 \mathrm{~km} \mathrm{x} 1 \mathrm{~km}$ and a national soil

418 dataset (INEGI, 2004) besides HWSD to assess the impact of higher resolution climate data and

419 regional soil data products, a major application opportunity for the methodology presented 
420 herein. Maize planting dates recorded in the year 2017 were obtained from SIAP (2018b). All

421 yields were de-trended linearly to correct for changes in management intensity.

422 2.6 Computational framework

423 All computations, evaluations and plotting were done within the R software environment

424 (R Development Core Team, 2008). Machine learning models were built using the packages

425 specified in sections 2.4.1 and 2.4.2. Figures were produced using ggplot2 (Wickham, 2009).

426 Statistical analyses beyond linear regression were carried out with hydroGOF (Zambrano-

427 Bigiarini, 2017).

\section{$428 \quad 3$ Results}

4293.1 Global scale model performance for crop yields

430 The global extreme gradient boosting meta-models for irrigated and rainfed maize yields

431 based on the full climate features show a near perfect fit and low mean bias in both cases (Figure

432 2a,b). Large over- and underestimations in predictions are rare. The first occur foremost at low

433 simulated yields, the latter at high ones with a negative trend beyond $12 \mathrm{t} \mathrm{ha}^{-1}$ (see Figure S3a,b

434 for residual plots). For rainfed yields, noticeable deviations in density distributions of EPIC

435 simulated and extreme gradient boosting predicted yields occur below $2 \mathrm{t} \mathrm{ha}^{-1}$ and around 6-7 t

$436 \mathrm{ha}^{-1}$ (Figure 2c). The density distributions are nearly identical for irrigated yields (Figure 2d). 
$\mathbf{a}$

count
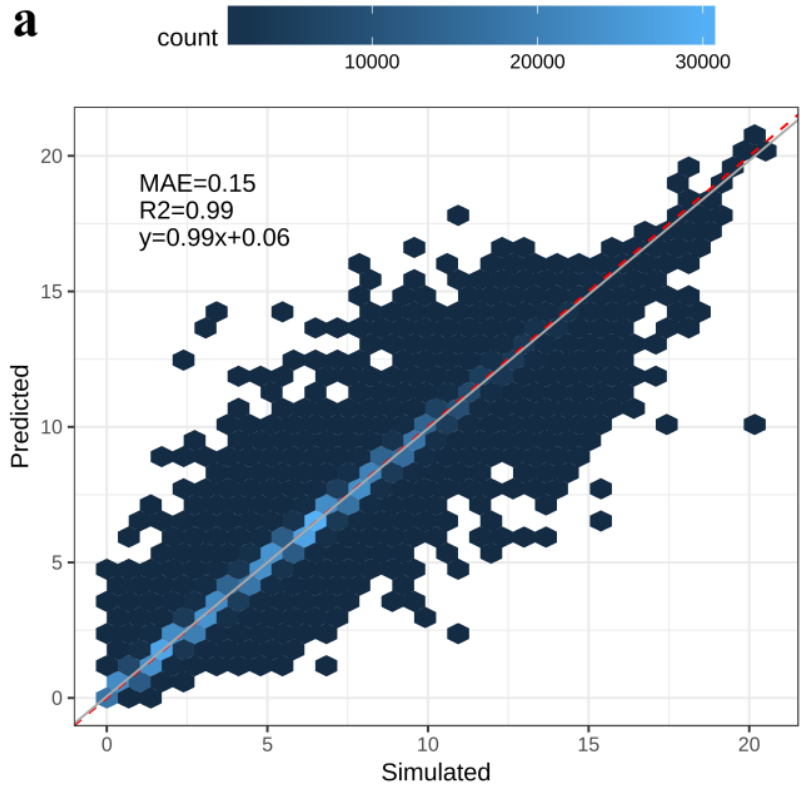

c

$\square$ Simulated i i Predicted

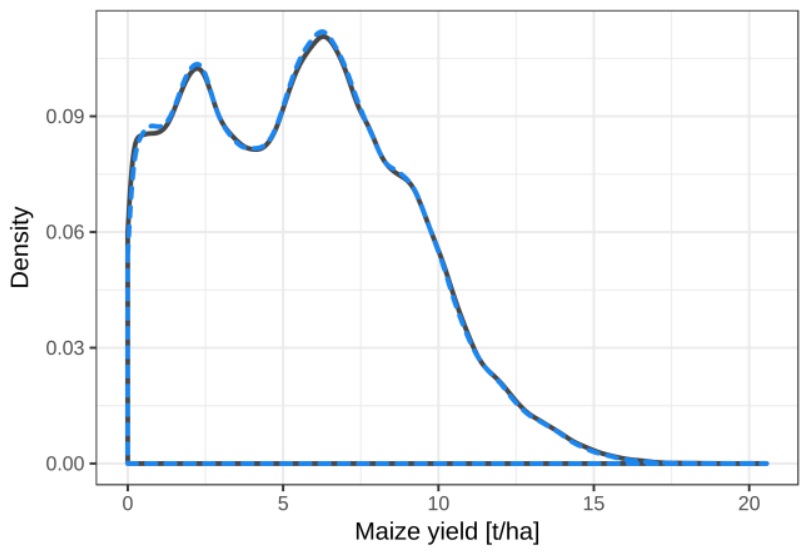

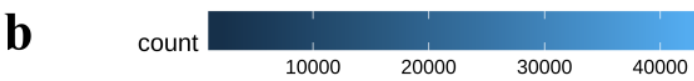

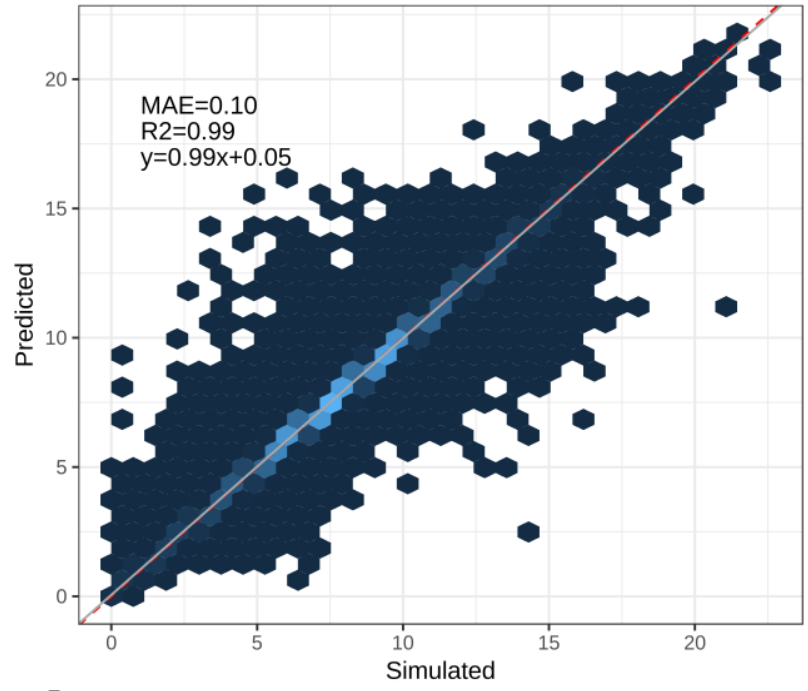

d

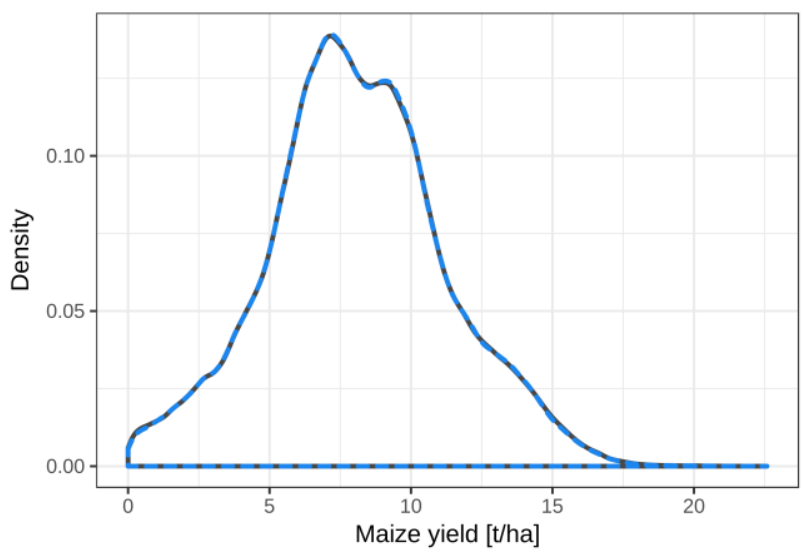

Figure 2. Hexbin and regression plots for EPIC simulated and extreme gradient boosting predicted crop yields in the validation dataset (25\% of total samples) for (a) rainfed and (b) irrigated conditions and corresponding density distributions for (c) rainfed and (d) irrigated conditions. Red dashed and grey solid lines in (a) and (b) show 1:1 line and regression, respectively. See section 3.4 and SI for random forest models. 
$444 \quad 3.2 .1 \quad$ General performance and patterns

445 The accuracy of rainfed and irrigated yield predictions for Mexico at a high spatial

446 resolution (Figure 3a,b) is nearly up to that of the global validation data with $97 \%$ of variance of

447 EPIC simulated yields explained by the extreme gradient boosting models in both cases. Slopes

448 of the linear regressions are lower and the intercepts are higher than at the global scale indicating

449 biases at the lower and upper bounds of simulated yields. MAE increases by up to $0.5 \mathrm{t} \mathrm{ha}^{-1}$ but

450 is still considerably low concerning the mean of crop yield estimates. Overestimations by $>100 \%$

451 occur in both water management scenarios with a cluster of data points around $3.5 \mathrm{t} \mathrm{ha}^{-1}$ of EPIC

452 simulated yields. These are related to remaining nitrogen stress in few simulations $(0.5 \%$ of

453 samples) due to extreme soil-climate combinations on which the automatic fertilizer application

454 of up to $500 \mathrm{~kg} \mathrm{~N} \mathrm{yr}^{-1}$ does not suffice to fulfill plant requirements caused by vast losses of $\mathrm{N}$ in

455 runoff. Removing these simulations has no discernible effect on model performance (Figure S4).

456 The distributions of rainfed yield estimates and predictions exhibit a bimodal pattern with

457 over- and underestimation especially at the lower bound where the peak is shifted by about $1 \mathrm{t}$

$458 \mathrm{ha}^{-1}$ (Figure 3c). This is to a lesser extent also the case for the distributions of irrigated yield

459 estimates and predictions (Figure 3d). In addition, irrigated yields predicted by the extreme

460 gradient boosting model exhibit clustering, i.e. with overestimation peaks around 4, 5.5, and $10 \mathrm{t}$

$461 \mathrm{ha}^{-1}$ and valleys at 3 and $12 \mathrm{t} \mathrm{ha}^{-1}$, while EPIC simulated yields show a smoother distribution.

462 Using the more parsimonious climate feature sets decreases model performance (Table

463 S5) similar to the global scale validation data (Table S4). The largest decrease occurs for the 
464 most set of growing season climate data, while again hardly any difference is found when using 465 the monthly climate features.
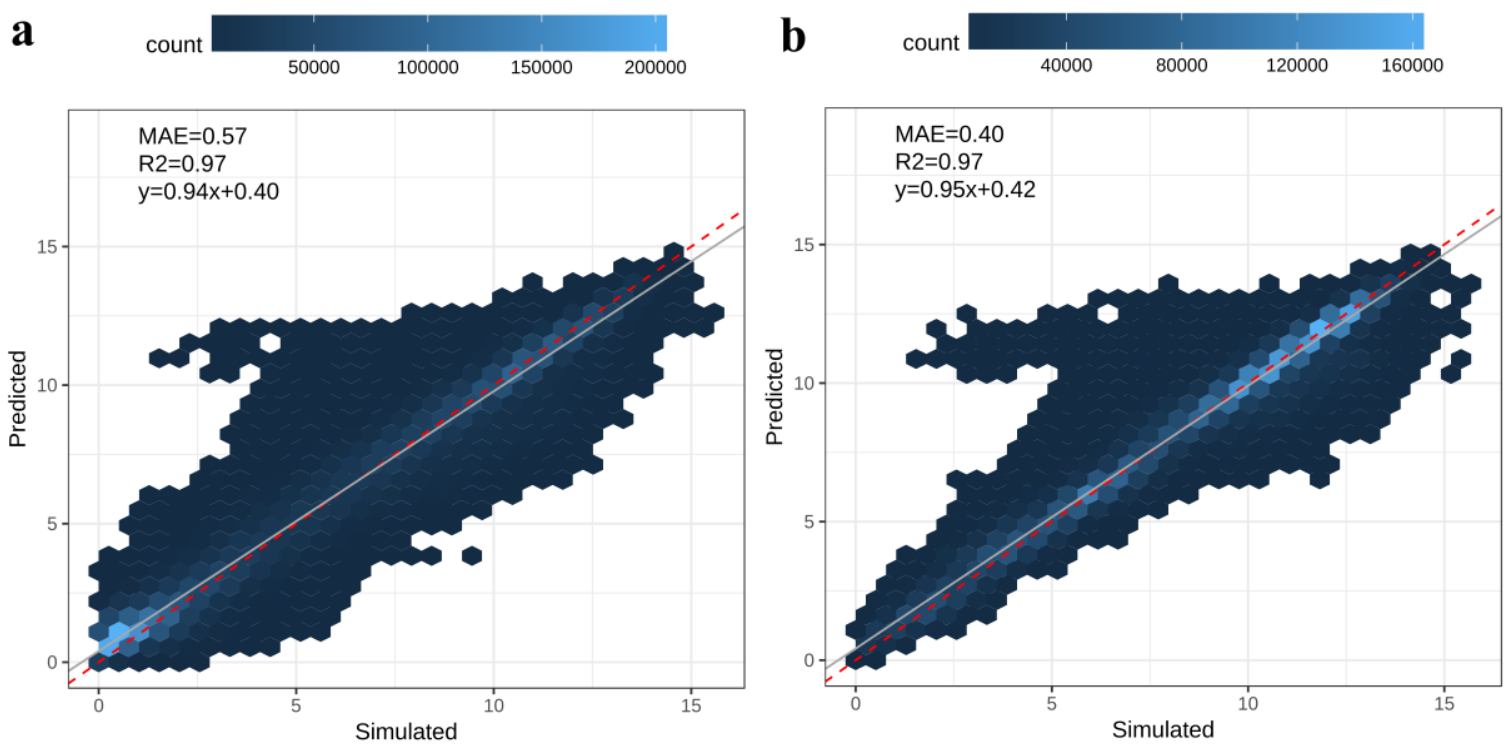

c

I-'

d

$\square$ Simulated $\quad i^{-1}$ Predicted
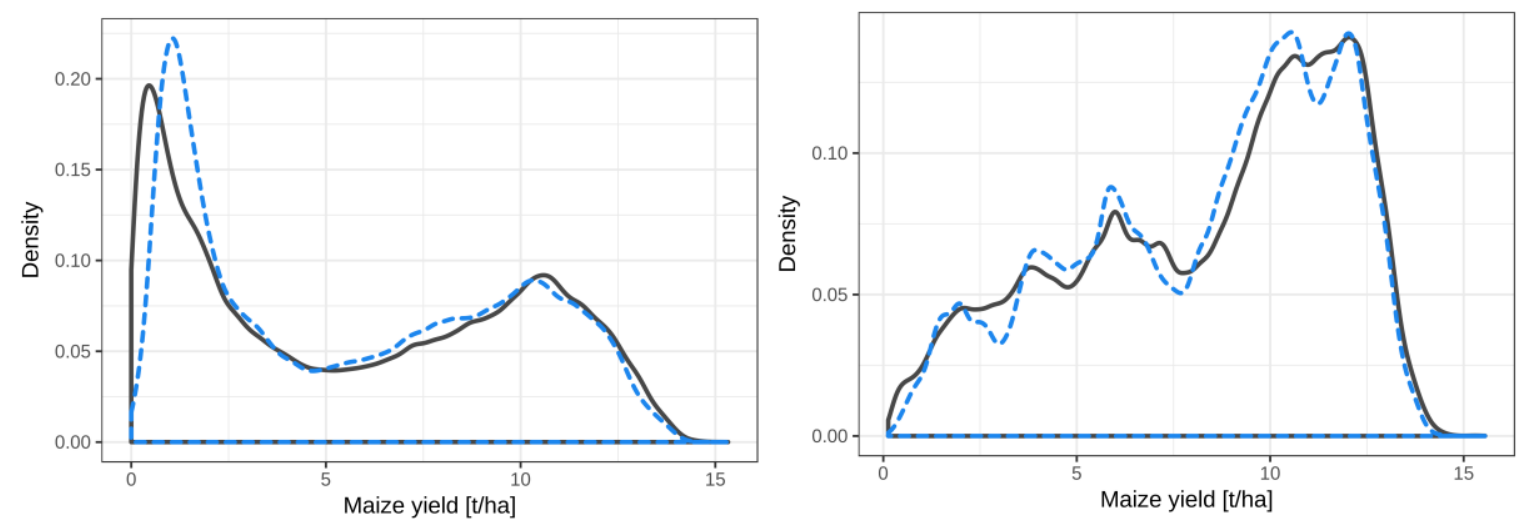

Figure 3. Same as Figure 2 but comparing the high-resolution downscaled predictions and benchmark EPIC simulations for Mexico. machine learning predictions at the scale of a single state of Jalisco for rainfed maize yields in 
471 the year 2000 shows that the machine learning predictions can fairly well reproduce the

472 heterogeneity seen in the high-resolution simulations (Figure 4a,c). Notable differences are

473 apparent in the region west of $-104.5^{\circ}$ and north of $20^{\circ}$, where the predictions are about $20 \%$

474 lower than the simulation results and parts of the southern and northern state where predictions

475 are up to $40 \%$ higher (Figure 4d). Overall, the distributions of yields agree fairly well (Figure

476 4b), but the predictions omit moderate and very high yields, indicating peaks around 7.5 and $9 \mathrm{t}$

$477 \mathrm{ha}^{-1}$ and a valley at $10.5 \mathrm{tha}^{-1}$, which are not present in the simulations. Still, yield predictions

478 and simulations are correlated with $\mathrm{R}^{2}=0.87$ (Figure S5a). 

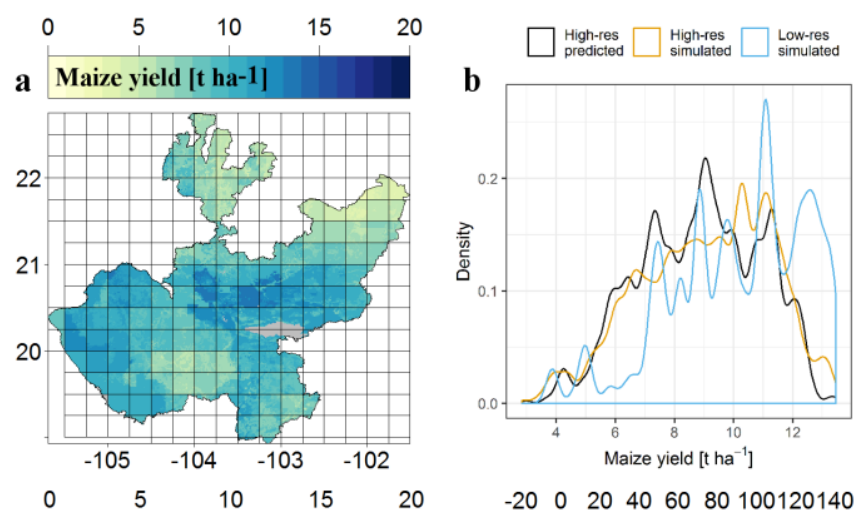

c Maize yield [t ha-1]

$-20 \quad 0 \quad 20406080100120140$

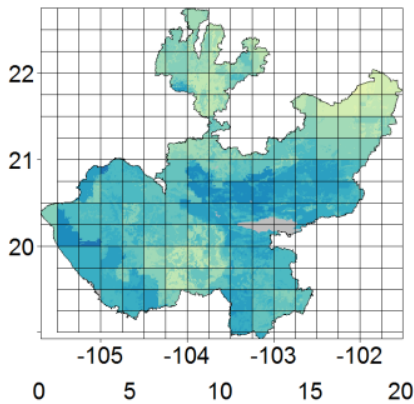

d Relative difference (c) to (a) [\%]

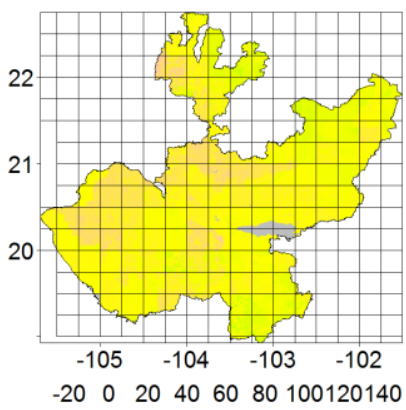

e Maize yield [t ha-1]
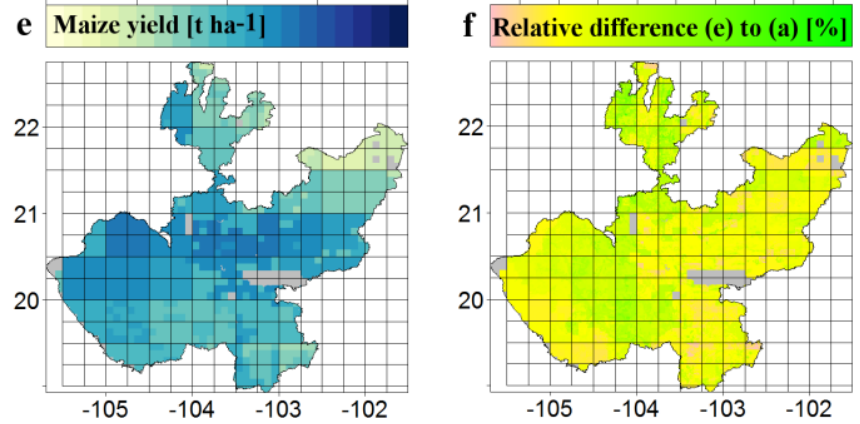

Figure 4. Examples of rainfed maize yields for the year 2000 in the state of Jalisco from (a) high-resolution EPIC simulation, (c) high-resolution machine learning prediction, and (e) global low-resolution simulation. (b) Shows the corresponding density distributions for which yield estimates from the low-resolution simulations have been resampled to the higher resolution to obtain at consistent sample sizes. (d) and (f) show the relative differences of (c) and (e) compared to (a), respectively. Regressions and statistics are presented in Figure S5a,b. The rectangular grid represents the $0.25^{\circ} \times 0.25^{\circ}$ climate grid. 
Expectedly, low-resolution EPIC estimates (Figure 4e) agree only with respect to large-

488 scale patterns. Substantial overestimation by up to $60 \%$ occur in the central parts and

489 underestimation by up to $30 \%$ foremost in the west but also scattered at the subgrid level (Figure

490 4f). The yield distribution is biased towards higher yield estimates (Figure 4b) and the coefficient

491 of determination is $\mathrm{R}^{2}=0.64$ (Figure $\mathrm{S} 5 \mathrm{~b}$ ). The arithmetic means at the state level are $9.06 \mathrm{tha}^{-1}$

492 for the high-resolution simulations, $8.85 \mathrm{tha}^{-1}$ for the predictions, and $10.15 \mathrm{t} \mathrm{ha}^{-1}$ for the low-

493 resolution simulations, corresponding to an overestimation by $11.98 \%$ for the low-resolution

494 simulations and an underestimation by $2.31 \%$ for the extreme gradient boosting predictions.

495 Hence, despite remaining differences, the high-resolution predictions reproduce the

496 corresponding simulations quite robustly compared to the EPIC outputs derived from more

497 granular input data.

$498 \quad 3.2 .2$ Reproduction of inter-annual crop yield variability

499 NSE is greater than zero in around $20-30 \%$ of all simulation units for predictions of

500 rainfed yields by the model based on calendar year climate features alone (Figure 5a-c). The

501 model trained with the full set of climate features in contrast shows a substantially better

502 performance, especially in tropic climates. If simulated and predicted yields are zero-centered

503 and only present cropland is considered, NSE performance turns out substantially better for both

504 feature sets (Figure 5d-f) and again to a very high degree for the extreme gradient boosting

505 model trained on the full climate feature set. 

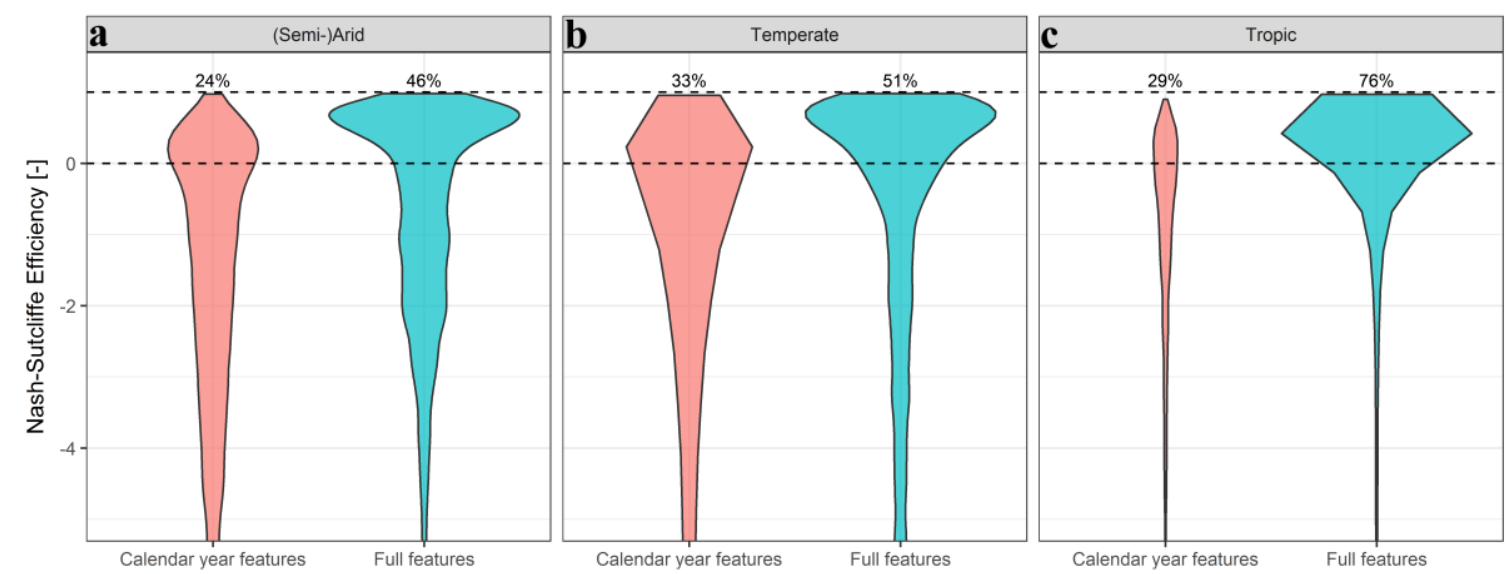

竞.
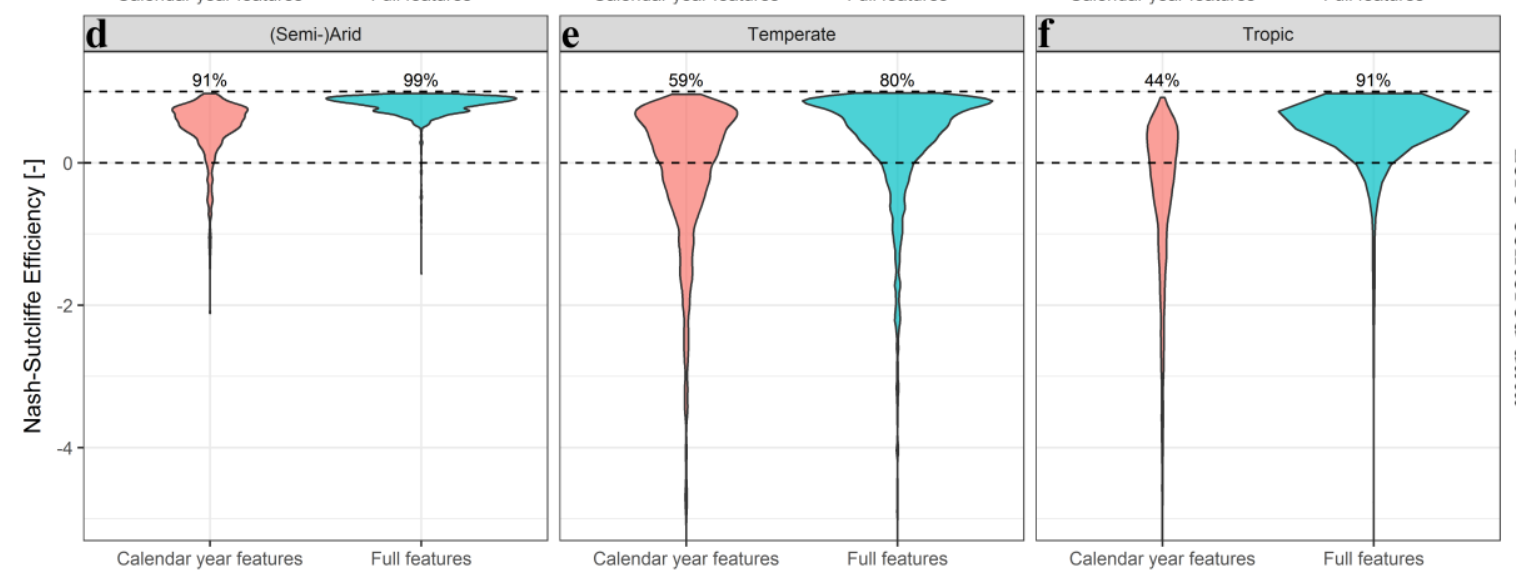

焉.

Figure 5. Violin plots of Nash-Sutcliffe Efficiency disaggregated by major Koeppen-Geiger climate regions (see section 2.5) for the feature subsets using calendar year climate variables only or all climate features. (a-c) All simulation units of Mexico with raw data or (d-f) only simulation units with $>5 \%$ maize harvest area and zero-centered yield variability. Percentages indicate the fraction of simulation units with NSE $>0$. to -5 for better readability. 
With sufficient irrigation water supply, NSE performance is overall lower while the

516 patterns remain quite similar, resulting in only few simulation units with NSE $>0$ for the model

517 based on annual climate data (Figure S6a-f). A key difference to rainfed yield estimates is the

518 lower performance in (semi-)arid regions, where inter-annual yield variability decreases

519 substantially if sufficient water is supplied.

520 At a higher level of spatial aggregation - here the arithmetic mean for major Koeppen-

521 Geiger climate regions -, inter-annual dynamics are well represented when considering all

522 simulation units (Figure 6a-c). Similar to the distributions presented above (Figure 5),

523 performance is best in tropic climates and poorest in (semi-)arid regions, but NSE is in all cases

524 well above zero and MAE $<0.25 \mathrm{t} \mathrm{ha}^{-1}$. If only present cropland is considered (Figure 6d-f),

525 performance decreases marginally in tropic and temperate climates, while it improves

526 substantially in (semi-)arid climate where mostly highly arid simulation units are now neglected

527 and predominantly simulation units with erratic rainfall remain (not shown). Foremost the latter

528 climate region shows that the yield predictions can quite well reflect both yield peaks and

529 valleys.

530 If sufficient irrigation water is supplied, the agreement with EPIC simulations in terms of

531 NSE decreases substantially in temperate climate if all simulation units are considered but

532 remains very similar in tropics and (semi-)arid climate (Figure S7a-c). For present cropland

533 alone, the agreement in terms of NSE decreases most in (semi-)arid climate compared to rainfed

534 yield estimates, followed by temperate regions. Predictions for the tropics still show very good

535 agreement. 

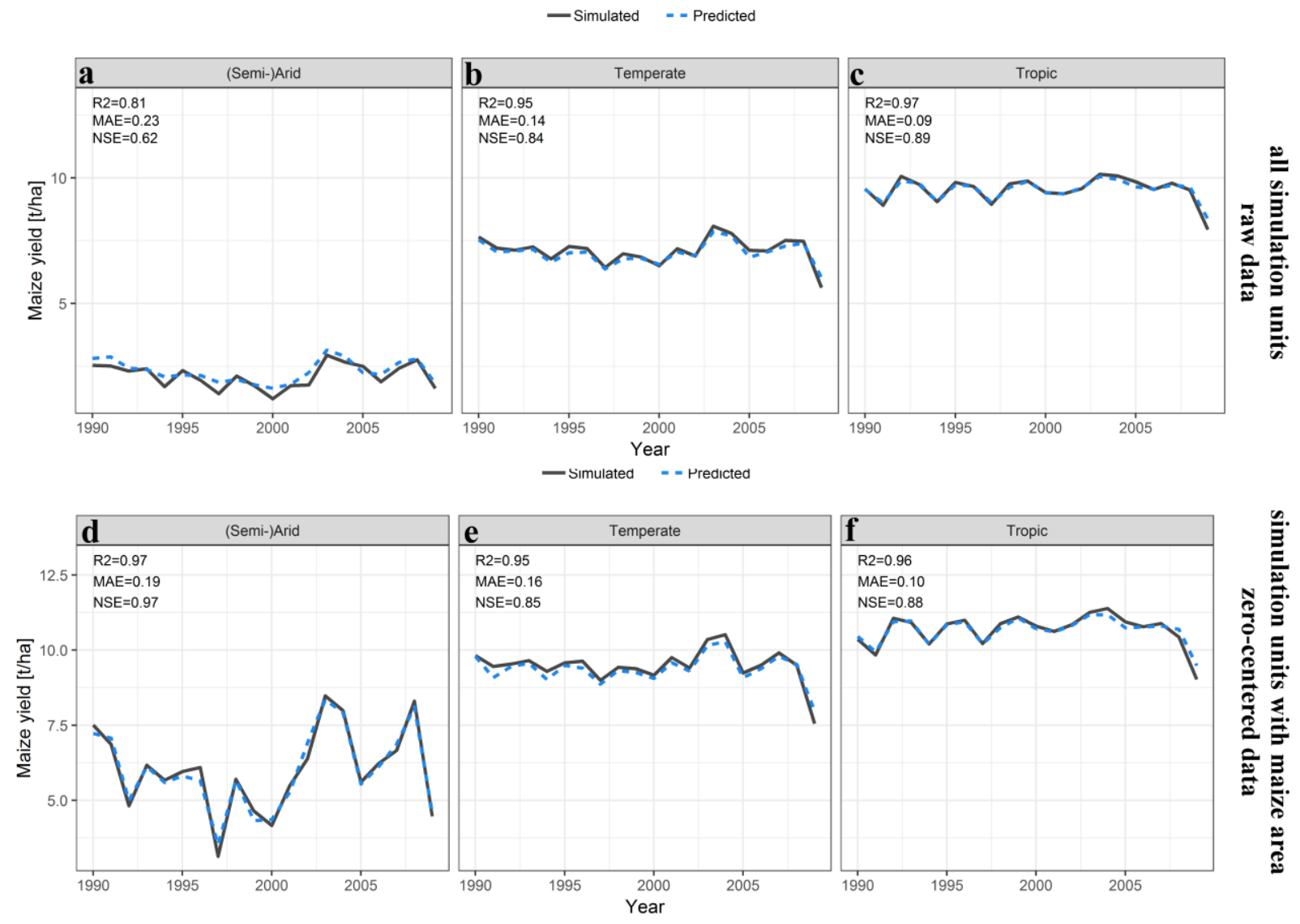

537 Figure 6. Inter-annual dynamics of mean rainfed yields for each Koeppen-Geiger climate region of Mexico (see section 2.5) considering (a-c) all simulation units or (d-f) only simulation units intersecting with substantial maize harvest areas (see section 2.3.4).

$540 \quad 3.3$ Feature importance and the role of feature engineering

With rainfed water supply only, the sum of precipitation during the growing season

542 (PRCPsumGS) is the by far most important predictor (Figure 7a), followed by calendar year

543 precipitation PRCPsumYRcal, PHU, and LVP. Temperature, radiation, and soil-related features

544 are of moderate to minor importance. Soil variables matter only with respect to water 
545 availability, driven by depth and PAW, which is a composite of texture, SOC, and depth. Other

546 soil variables, which are mostly related to nutrient availability, matter less due to the estimation

547 of yield potentials. With sufficient irrigation, the temporally static cultivar and management

548 characteristics PHU and LVP are the most important features, followed by the annual growing

549 degree day sum GDDsumYRcal and a wider set of transient climate features, which are

550 expectedly related to temperature and solar radiation (Figure 7b). Precipitation and ET-related

551 features do not occur among the top ranking features except for CMD_4. Among the soil

552 characteristics, again depth and PAW are the most relevant features.

553 Comparing the variable importance of different subsets of features for model training

554 (Figure S8; see Table 2 for feature subsets) shows that for rainfed water supply, precipitation-

555 and cultivar-related features are consistently the most important predictors (Figure S8a,c,e).

556 Beyond, the ranking of features depends on the feature set with PET derivatives exhibiting rather

557 low importance among climate features. Notably, soil characteristics beyond depth and PAW are

558 typically lowest ranking if occurring at all. With sufficient irrigation water supply, PHU and

559 LVP are consistently the most important features (Figure S8b,d,f) followed predominantly by

560 temperature and radiation indices. As for rainfed yield estimates, depth and PAW occur in all

561 feature set as moderately higher-ranking covariates. Precipitation- and PET-related features are

562 only present in the parsimonious models with 23 features in total, except for CMD_4 in the

563 model based on monthly features. 

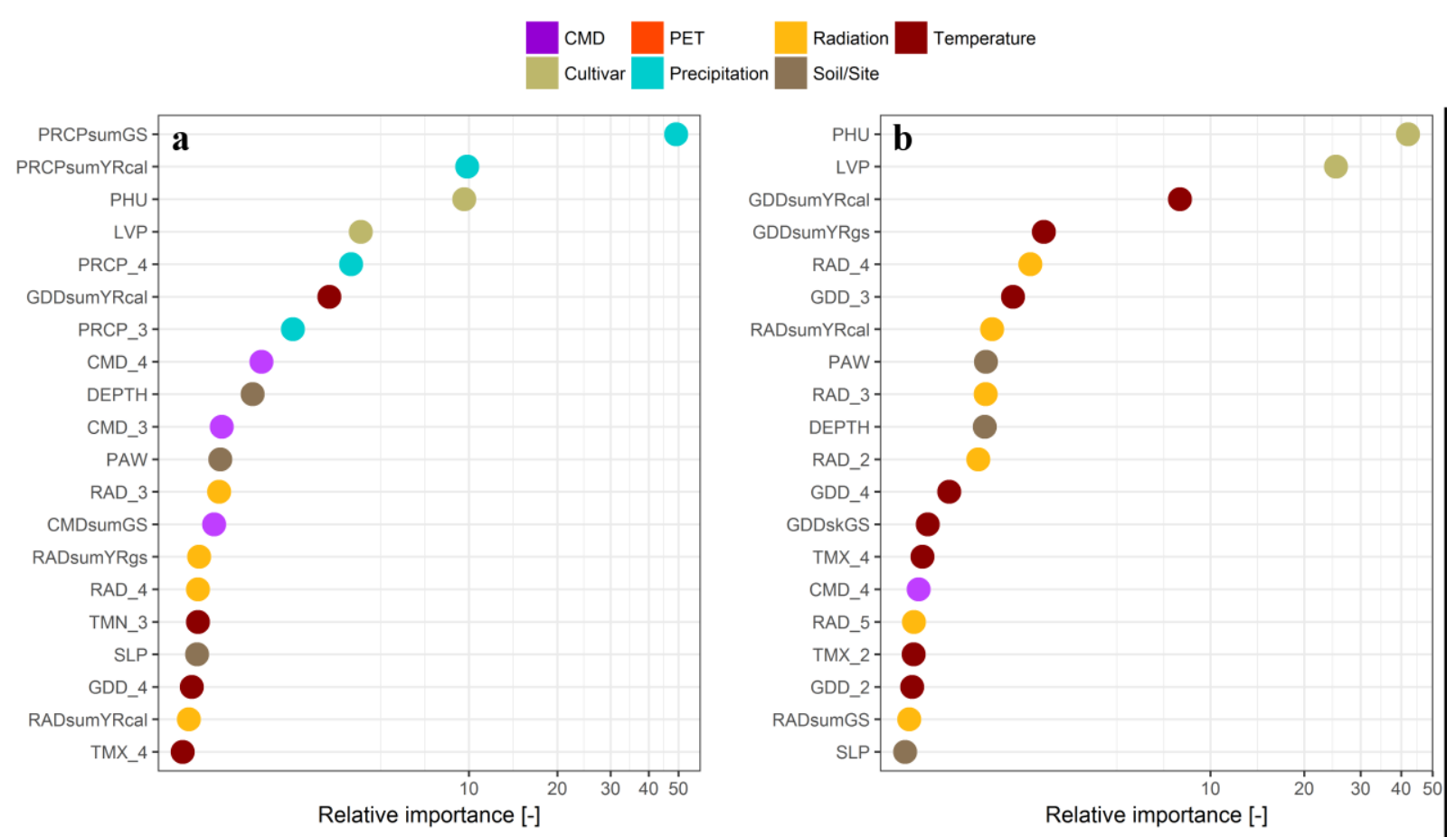

Figure 7. Feature importance for the extreme gradient boosting models for (a) rainfed and (b) irrigated conditions. Only top 20 features (see Table 1 for details) are shown. The $\mathrm{x}$-axis is $\log (\mathrm{x}+1)$ transformed for better readability.

3.4 Random forests models compared to extreme gradient boosting

570 are highly comparable to those from extreme gradient boosting (Table S4) with a marginal

571 tendency towards lower slopes and higher intercept and slope under rainfed conditions.

572 Predictions for Mexico in turn (Table S5) result typically in slightly higher intercepts and MAE

573 as well, but higher $\mathrm{R}^{2}$ especially for the parsimonious feature sets under irrigated conditions.

575 covariates under rainfed water management, the numbers of simulation units with NSE $>0$ are in 
576 all cases lower or virtually equal (Table S8; c.f. Table S6). Most notable difference are apparent

577 for the models trained on the full climate feature set in tropic regions. This is even more

578 pronounced for irrigated conditions, where the number of simulation units with NSE $<0$ is up to

$57940 \%$ lower than the extreme gradient boosting predictions (Table S9; c.f. Table S7).

580 Accordingly, predictions aggregated to Koeppen-Geiger regions show also a poorer fit,

581 but differences are here less pronounced and apparent foremost in NSE statistics (Figure S12 and

582 Figure S13). This is most evident under rainfed conditions in (semi-)arid regions if all simulation

583 units are considered (Figure S12a-c). Under irrigated conditions, NSE is even negative in (semi-

584 )arid climates, no matter whether all simulation units are considered or present cropland only,

585 (Figure S13a,d) and in temperate climate if all simulation units are considered (Figure S13b).

$586 \quad$ Variable importance remains structurally similar among feature subsets and water supply

587 regimes (Figure S14) compared to extreme gradient boosting (Figure 7; Figure S8) concerning

588 the overall ranking of features with some predictors moving up or down a few positions. A

589 striking differences, however, is that random forests rank also variables indicating distributions,

590 i.e. standard deviation, among the more important features, while extreme gradient boosting

591 predictions are foremost relying on sums and averages.

5923.5 Reproduction of reported inter-annual yield variability

593 The evaluation of inter-annual yield variability for the top producing municipios in

594 Jalisco (Figure S15) shows that NSE is positive in the majority of municipios and hence

595 satisfactory in all crop yield predictions from both EPIC and the extreme gradient boosting

596 models. Lowest median performance was found for the global simulations (EPIC global), 
597 followed by the high-resolution EPIC simulations at the scale of Mexico (EPIC high-res) with a

598 slight tendency towards higher NSE. Interestingly, the median NSE for extreme gradient

599 boosting predictions (Predicted high-res) is higher than for the EPIC simulations at the same

600 resolution. This is mainly due to one municipio with rather poor performance in the simulations,

601 while the predictions (Predicted high-res) do not achieve very high performance in other

602 municipios where EPIC simulations result in up to NSE=0.8. The overall best rendition of inter-

603 annual yield variability is produced by the machine learning predictions using 1k-resolution

604 monthly climate surfaces (Predictions $1 \mathrm{k}$ ) and more so if a national soil data product is used

605 (Predictions 1k CRU x INEGI) with a median NSE of 0.42 as opposed to 0.20 in the high-

606 resolution EPIC simulations (EPIC high-res). The CRU x HWSD combination in contrast results

607 in a lower median but higher maximum NSE.

\section{Discussion and Conclusions}

609 4.1 Model performance for downscaling of yield estimates

610 Performance of the meta-models for spatio-temporal downscaling of crop yield estimates

611 is exceptionally high in terms of linear regression statistics, and mean bias for both machine

612 learning methods (Table S4; Table S5). While the results are highly comparable among the two

613 methods, extreme gradient boosting shows moderately better results especially for inter-annual

614 yield variability (cf. Tables S6-9), which is of ample importance for climate impact studies (e.g.

615 Müller et al., 2017). In essence, substantial deviations of predictions from EPIC simulations

616 occur only for very low yields. Even here, this applies foremost to their absolute magnitude

617 while inter-annual yield variability is typically still very well reproduced although this is not an 
618 implicit goal of the machine learning model optimization. In addition, the high skill in

619 reproducing irrigated yields stands out, as crop yield variability is known to be more strongly

620 dominated by variability in precipitation than temperature in most regions (e.g. Frieler et al., 621 2017).

622 Our results can hardly be compared to existing literature, as the spatio-temporal

623 downscaling of crop model outputs via meta-models has not yet been addressed to the authors'

624 knowledge. Within the closely related, recently emerging field of crop model emulators, Blanc

625 and Sultan (2015) and Blanc (2017) developed polynomial models to predict yields for various

626 crops under climate change using unique parameterizations for the statistical models at the grid

627 cell level. Besides weather and soil data, they include $\mathrm{CO}_{2}$ as an additional dimension. These

628 structural differences (a) grid-cell level in the references vs scale-free approach here and (b) no

$629 \mathrm{CO}_{2}$ dimension in the present study render the comparison of results difficult. The authors of the

630 cited studies conclude that the statistical models provide reasonable results in the longer term.

631 However, the visual comparison of inter-annual yield variability for the Corn Belt during the

632 historic time period in Blanc and Sultan (2015) and the regional predictions presented in this

633 study suggest that the polynomial models may be suitable at the global scale and for longer term

634 assessments but not for regional impact studies. A similar statistical approach has been employed

635 by Oyebamiji et al. (2015) for a single GGCM finding that 62-93\% of crop yield variability

636 produced by the GGCM can be explained by their multiple tier statistical model, which was as

637 well parameterized at the grid cell level. This indicates that so far no other methodologic

638 approaches can provide as accurate and flexible crop meta-models as the ones presented herein, 
639 which are also virtually scale-free, free from a priori assumptions on relevant features, and truly

640 data-driven.

641 The very high accuracy of the machine learning models also allowed for detection of an

642 anomaly in the high-resolution EPIC simulations for Mexico, in which the automatic fertilizer

643 application failed due to extreme combinations of climate and soil (see Figure 3a,b and

644 associated text). This indicates that the method should also be tested for quality control of crop

645 model simulations.

$646 \quad 4.2$ Feature engineering and feature importance

647 The evaluation of different feature subsets shows that even very basic features from

648 annual climate provide robust results when it comes to general regression metrics. This

649 highlights that these features should contain sufficient information for providing at least long-

650 term mean crop yield and agricultural externalities surfaces. Monthly climate data are essential,

651 in contrast, to provide predictions of very high accuracy (Table S4, Table S5) and to capture

652 inter-annual crop-climate response accurately as reflected in the EPIC model (Figure 6). This can

653 be expected as crop growth processes are typically non-linear (Bonhomme, 2000) and crops'

654 sensitivity to temperature and water supply can shift throughout the growing season. That is, for

655 instance, the case for drought stress susceptibility of maize yield formation, which is largest

656 during the second half of the growth cycle for maize (e.g. Gaiser et al., 2010) and is reflected in

657 the EPIC model within the calculation of an actual HI based on water stress (see section 2.1).

658 The feature importance of models for rainfed yield prediction is quite straightforward

659 with precipitation and other water-related features strongly dominating (Figure 7a). Static 
660 variables PHU and LVP follow thereafter, rendering water availability the main driver for inter-

661 annual yield variability, while especially PHU - a composite of growing season length and long-

662 term temperatures - may rather serve as a proxy for the overall yield potential and thermal

663 growth conditions. If monthly climate statistics are considered, the third and fourth months have

664 the largest influence on rainfed yield predictions. This relates to the aforementioned non-linearity

665 of crop growth requirements and the crop's higher sensitivity during the second half of the 666 growing season.

If sufficient water is supplied (Figure 7b), temperature- and solar radiation-related

668 features come to the fore. In the first case, these are not minimum or maximum temperatures

669 indices as such, but again growth effective temperature sums (here GDD). This corresponds

670 directly to the estimation of phenologic development in the EPIC model (see section 2.1), which

671 is driven by HU accumulation, while very high and very low temperatures cause stresses to the

672 crop, which is over large areas typically of minor importance compared to water deficits (e.g.

673 Schauberger et al., 2017). It is striking, however, that among the transient climate features, not

674 the growing season sum of GDD (GDDsumGS) is the most important feature, but annual GDD

675 (GDDsumYRcal). An explanation is that growing season features were calculated for the months

676 of the average length of vegetation period (feature LVP). Hence, GDDsumGS may in some years

677 exceed or fall below the actual PHU requirement, while GDDsumYRcal is a more robust annual

678 temperature index.

679 The low importance of soil covariates can be expected due to the simulation of yield

680 potentials. As shown in an earlier study (Folberth et al., 2016), the EPIC model itself is rather

681 insensitive to soil data if yield potentials are simulated, even more so with sufficient irrigation. 
682 Hence, the only soil covariates of relevance here relate to water availability, i.e. soil depth and

683 PAW. Nutrient-related soil covariates in turn may even outweigh the importance of climate

684 features if no or little nutrients are supplied exogenously as nutrient supply can affect crop yields

685 by more than an order of magnitude (e.g. Folberth et al., 2013). Still, the spatial detail in Figure

$6864 \mathrm{a}, \mathrm{b}$ shows that despite the low importance of soil and site covariates, yield patterns are very

687 well reproduced at the sub-climate grid $\left(0.25^{\circ} \times 0.25^{\circ}\right)$ level. This indicates that the soil and site

688 signal is sufficiently represented in the crop yield meta-model despite the comparably low

689 ranking of soil and site features (Figure 7). An increase in the importance of soil and site features

690 was found for the meta-model to predict crop available water (Supplementary Text S2), where

691 various hydrologically relevant covariates such as slope and soil hydrologic group rank higher

692 than for crop yield predictions or GSET (Figure S11). This emphasizes that approaches free from

693 assumptions on feature importance are required at least when moving away from crop yield

694 predictions towards agricultural externalities.

6954.3 Predictions of agricultural externalities

Agricultural externalities were assessed supplementary (Supplementary Text S2) to

697 evaluate the potential of machine learning algorithms to predict these as well, which is an

698 essential advantage of integrated crop growth models compared to purely statistical methods of

699 crop yield estimation. The very good results for GSET show that this is in principle feasible. The

700 slightly lower performance for CAW in turn indicates that there are limits under extreme

701 conditions: The very high values that are underestimated here (Figure S9c,d) occur in simulation

702 units with moderate to high precipitation, low slopes, and soils with high infiltration potential

703 (not shown). Capturing also such combinations may require an extension of the training data set 
704 (see section 4.6). Overall, however, the results show that the computational framework used for

705 yield predictions can flexibly be transferred to other crop model outputs. Limitations can still be

706 expected for agro-environmental externalities that occur intermittently with daily peaks such as

707 emissions of certain greenhouse gases.

708 4.4 Differences and advantages of employed machine learning approaches

709 Differences between the applied machine learning algorithms have been touched upon

710 above and are here summarized and complemented. In this study, random forests were found to

711 have lower performance in predictions with respect to inter-annual yield variability but showed

712 overall similar predictive accuracy, while also the importance of features for crop yield

713 predictions remained comparable (see section 3.4). From a practical point, however, the

714 computational cost of random forests is far higher than that of extreme gradient boosting. In the

715 case of the full climate feature set, it was here about nine hours versus one on the same 32 core

716 cluster (Figure S16). Even if the number of trees was reduced, which may not cause substantial

717 trade-offs in accuracy (Figure S1), the time requirement can be assumed at least four times

718 higher. While common gradient boosting methods may show low computational performance

719 due to sequential tree building, the extreme gradient boosting approach has markedly high

720 efficiency due to parallelization as already evaluated in its original publication (Chen and

721 Guestrin, 2016).

722 Although the quantification of prediction uncertainty is beyond the scope of this study, it

723 is worth mentioning that for random forests there are established methods to quantify prediction

724 intervals and hence uncertainties associated with predictions (e.g. Meinshausen, 2006) for which 
725 no readily applicable methods have been developed for gradient boosting. Provided that the

726 meta-model predictions show very high accuracy but outliers still occur, this may become of

727 great importance for applications of downscaled yield estimates e.g. in land use change studies as

728 well as in the quantification of trade-offs and benefits of (potential) meta-model error and

729 improved coverage of landscape heterogeneity. We can hence conclude that within the scope of

730 this study, the extreme gradient boosting approach appears most suitable, but still the selection of

731 the most appropriate method needs to be made on a per case basis of a specific study.

732 4.5 Model performance benchmarked against reported local yields

733 The performance evaluation against reported yields for ten major producing municipios

734 (Section 3.5) shows that both EPIC and the extreme gradient boosting models perform

735 satisfactorily for major producing regions. Thereby, the use of high-resolution monthly climate

736 surfaces substantially improves the quality of yield predictions. Further targeted evaluations

737 beyond the scope of this paper will be required to assess under which circumstance the crop

738 model itself or the meta-model may perform better or poorer and what the impact of

739 uncertainties and spatial resolutions in climate, soil, management, and land use data as well as

740 crop model parameterization or meta-model error is as has been done before for single crop

741 models (Folberth et al., 2012a) and crop model ensembles (e.g. Angulo et al., 2014).

\section{$742 \quad 4.6$ Outlook}

743 The meta-models presented herein can readily provide robust estimates within the

744 domain of the training data, providing a solid proof of concept that machine learning bears great

745 potential for building readily applicable crop meta-models for spatio-temporal downscaling 
746 applications. It is likely, however, that regional and specific local conditions are not represented

747 within the global feature ranges and their combinations. In addition, crop cultivars are often

748 adapted to regional conditions, e.g. in terms of temperature requirements and maturity classes.

749 Here, we found that specific, extremely rare climate-soil combinations led to a systematic

750 underestimation of the growing season soil water balance CAW. An option to train a meta-model

751 for such conditions in a systematic way is to simulate artificial combinations of atmospheric,

752 soil, cultivar, and management conditions that go beyond the combinations inherently occurring

753 in the global database. This allows for covering an enhanced space of potentially prevailing plant

754 growth conditions at finer resolutions. A similar approach has recently been undertaken within

755 the GGCMI initiative (Elliott et al., 2015), altering atmospheric and management conditions in

756 each simulation unit (resp. $0.5^{\circ} \times 0.5^{\circ}$ grid cell) along the dimensions $\mathrm{CO}_{2}$, temperature,

757 precipitation, and $\mathrm{N}$ fertilizer (CTWN; Ruane et al., 2017) to develop crop model emulators for

758 climate change impact studies among others. This can hence serve as a blueprint for extending as

759 well the training data extent as well as its dimensionality for a wider range of applications and

760 environments.

762 Acknowledgements

763 C.F., J.B., R.S., and M.O. were supported by European Research Council Synergy grant

764 ERC-2013-SynG-610028 Imbalance-P. Support from the Basic Research Program of the

765 National Research University Higher School of Economics for A.B. is gratefully acknowledged.

766 All data and scripts required for training machine learning algorithms and evaluating against

767 EPIC benchmark simulations are accessible online at 
768 http://webarchive.iiasa.ac.at/ folberth/downscaling_paper/. The authors declare no conflicts of

769 interest.

770 References

771 Ali, I., Greifeneder, F., Stamenkovic, J., Neumann, M., \& Notarnicola, C. (2015). Review of

772 Machine Learning Approaches for Biomass and Soil Moisture Retrievals from Remote

773 Sensing Data. Remote Sensing, 7(12), 16398-16421. https://doi.org/10.3390/rs71215841

774 Balkovič, J., van der Velde, M., Skalský, R., Xiong, W., Folberth, C., Khabarov, N., ...

775 Obersteiner, M. (2014). Global wheat production potentials and management flexibility

776 under the representative concentration pathways. Global and Planetary Change, 122,

777 107-121. https://doi.org/10.1016/j.gloplacha.2014.08.010

778 Blanc, E., \& Sultan, B. (2015). Emulating maize yields from global gridded crop models using

779

780 statistical estimates. Agricultural and Forest Meteorology, 214-215, 134-147. https://doi.org/10.1016/j.agrformet.2015.08.256

781 Blanc, É. (2017). Statistical emulators of maize, rice, soybean and wheat yields from global

782 gridded crop models. Agricultural and Forest Meteorology, 236, 145-161.

$783 \quad$ https://doi.org/10.1016/j.agrformet.2016.12.022

784 Bonhomme, R. (2000). Bases and limits to using 'degree.day' units. European Journal of

785 Agronomy, 13(1), 1-10. https://doi.org/10.1016/S1161-0301(00)00058-7

786 Breiman, L. (2001). Random Forests. Machine Learning, 45(1), 5-32.

$787 \quad$ https://doi.org/10.1023/A:1010933404324 
Chen, T., \& Guestrin, C. (2016). XGBoost: A Scalable Tree Boosting System. In Proceedings of the 22Nd ACM SIGKDD International Conference on Knowledge Discovery and Data Mining (pp. 785-794). New York, NY, USA: ACM. https://doi.org/10.1145/2939672.2939785

Delerce, S., Dorado, H., Grillon, A., Rebolledo, M. C., Prager, S. D., Patiño, V. H., ... Jiménez, D. (2016). Assessing Weather-Yield Relationships in Rice at Local Scale Using Data Mining Approaches. PLOS ONE, 11(8), e0161620. https://doi.org/10.1371/journal.pone.0161620

Duro, D. C., Franklin, S. E., \& Dubé, M. G. (2012). A comparison of pixel-based and objectbased image analysis with selected machine learning algorithms for the classification of agricultural landscapes using SPOT-5 HRG imagery. Remote Sensing of Environment, 118, 259-272. https://doi.org/10.1016/j.rse.2011.11.020

Elliott, J., Müller, C., Deryng, D., Chryssanthacopoulos, J., Boote, K. J., Büchner, M., ... Sheffield, J. (2015). The Global Gridded Crop Model Intercomparison: data and modeling protocols for Phase 1 (v1.0). Geosci. Model Dev., 8(2), 261-277. https://doi.org/10.5194/gmd-8-261-2015

EROS Data Center (2000), Global Land Cover Characteristics Database v2.0. https://lta.cr.usgs.gov/glcc/globdoc2_0, USGS Long Term Archive.

Ewert, F., van Ittersum, M. K., Heckelei, T., Therond, O., Bezlepkina, I., \& Andersen, E. (2011). Scale changes and model linking methods for integrated assessment of agri- 
environmental systems. Agriculture, Ecosystems \& Environment, 142(1), 6-17. https://doi.org/10.1016/j.agee.2011.05.016

FAO/IIASA/ISRIC/ISS-CAS/JRC (2012). Harmonized World Soil Database v1.21. http://webarchive.iiasa.ac.at/Research/LUC/External-World-soil-database/HTML/, International Institute for Applied Systems Analsysis, Laxenburg, Austria.

813 Fernández-Delgado, M., Cernadas, E., Barro, S., \& Amorim, D. (2014). Do we Need Hundreds of Classifiers to Solve Real World Classification Problems? Journal of Machine Learning Research, 15, 3133-3181.

Fick, S. E., \& Hijmans, R. J. (2017). WorldClim 2: new 1-km spatial resolution climate surfaces for global land areas. International Journal of Climatology, 37(12), 4302-4315.

Fischer, G., F. Nachtergaele, O. Prieler, S. Teixeira, E. Tóth, G. van Velthuizen, H. Verelst, L. Wiberg, D. (2012). Global Agro-Ecological Zones (GAEZ v3.0): Model Documentation. International Institute for Applied Systems Analysis, Laxenburg, Austria and FAO,

825 Folberth, C., Yang, H., Wang, X., \& Abbaspour, K. C. (2012a). Impact of input data resolution 826 and extent of harvested areas on crop yield estimates in large-scale agricultural modeling 827 for maize in the USA. Ecological Modelling, 235-236, 8-18.

$828 \quad$ https://doi.org/10.1016/j.ecolmodel.2012.03.035 
829 Folberth, C., Gaiser, T., Abbaspour, K. C., Schulin, R., \& Yang, H. (2012b). Regionalization of a large-scale crop growth model for sub-Saharan Africa: Model setup, evaluation, and estimation of maize yields. Agriculture, Ecosystems \& Environment, 151, 21-33.

833 Folberth, C., Yang, H., Gaiser, T., Abbaspour, K. C., \& Schulin, R. (2013). Modeling maize https://doi.org/10.1016/j.agee.2012.01.026

Folberth, C., Skalský, R., Moltchanova, E., Balkovič, J., Azevedo, L. B., Obersteiner, M., \& yield responses to improvement in nutrient, water and cultivar inputs in sub-Saharan Africa. Agricultural Systems, 119, 22-34. https://doi.org/10.1016/j.agsy.2013.04.002

Frieler, K., Schauberger, B., Arneth, A., Balkovič, J., Chryssanthacopoulos, J., Deryng, D., ... Levermann, A. (2017). Understanding the weather signal in national crop-yield variability. Earth's Future, 5(6), 605-616. https://doi.org/10.1002/2016EF000525

843 Gaiser, T., de Barros, I., Sereke, F., \& Lange, F.-M. (2010). Validation and reliability of the Velde, M. van der. (2016). Uncertainty in soil data can outweigh climate impact signals in global crop yield simulations. Nature Communications, 7, 11872. https://doi.org/10.1038/ncomms11872 EPIC model to simulate maize production in small-holder farming systems in tropical sub-humid West Africa and semi-arid Brazil. Agriculture, Ecosystems \& Environment, 135(4), 318-327. https://doi.org/10.1016/j.agee.2009.10.014

Gassman, P.W., Williams, J.R., Benson, V.W., Izaurralde, R.C., Hauck, L.M., Jones, C.A., Atwood, J.D., Kiniry, J.R., \& Flowers, J.D. (2004). Historical Development and 
Applications of the EPIC and APEX models. ASAE/CSAE Meeting Paper No. 042097. Retrieved from https://www.card.iastate.edu/products/publications/pdf/05wp397.pdf

851

Gerik, T., Williams, J., Francis, L., Greiner, J., Magre, M., Meinardus, A., Steglich, E., \& Taylor, R. (2015). Environmental Policy Integrated Climate Model - User's Manual Version 0810. Blackland Research and Extension Center, Texas A\&M AgriLife, Temple, USA. Retrieved from http://agrilife.org/epicapex/files/2015/10/EPIC.0810-User-Manual-Sept15.pdf

Global Land Cover 2000 database (2003). European Commission, Joint Research Centre, Ispra, Italy. Retreived from https://forobs.jrc.ec.europa.eu/products/glc2000/glc2000.php

Havlík, P., Schneider, U. A., Schmid, E., Böttcher, H., Fritz, S., Skalský, R., ... Obersteiner, M. (2011). Global land-use implications of first and second generation biofuel targets. Energy Policy, 39(10), 5690-5702. https://doi.org/10.1016/j.enpol.2010.03.030

Haylock M. R., Hofstra N., Klein Tank A. M. G., Klok E. J., Jones P. D., \& New M. (2008). A European daily high-resolution gridded data set of surface temperature and precipitation for 1950-2006. Journal of Geophysical Research: Atmospheres, 113(D20). https://doi.org/10.1029/2008JD010201

Hengl, T., Jesus, J. M. de, Heuvelink, G. B. M., Gonzalez, M. R., Kilibarda, M., Blagotić, A., ... Kempen, B. (2017a). SoilGrids250m: Global gridded soil information based on machine learning. PLOS ONE, 12(2), e0169748. https://doi.org/10.1371/journal.pone.0169748

Hengl, T., Leenaars, J. G. B., Shepherd, K. D., Walsh, M. G., Heuvelink, G. B. M., Mamo, T., .. Kwabena, N. A. (2017b). Soil nutrient maps of Sub-Saharan Africa: assessment of soil 
nutrient content at $250 \mathrm{~m}$ spatial resolution using machine learning. Nutrient Cycling in Agroecosystems, 109(1), 77-102. https://doi.org/10.1007/s10705-017-9870-x

872 INEGI, 2004. Información Nacional sobre Perfiles de Suelo v1.2. Instituto Nacional de

$873 \quad$ Estadística, Geografía e Informática. http://www.inegi.org.mx/geo/contenidos/recnat/edafologia/

875 Izaurralde, R. C., Williams, J. R., McGill, W. B., Rosenberg, N. J., \& Jakas, M. C. Q. (2006). 876 Simulating soil C dynamics with EPIC: Model description and testing against long-term

Izaurralde, R.C., McGill, W.B., \& Williams, J.R. (2012). Development and application of the data. Ecological Modelling, 192(3), 362-384. https://doi.org/10.1016/j.ecolmodel.2005.07.010

Jarvis, A., Reuter, H.I., Nelson, A., \& Guevara, E. (2008). Hole-filled SRTM for the globe EPIC model for carbon cycle, greenhouse gas mitigation, and biofuel studies. In: Liebig, M.A., Franzluebbers, A.J., \& Follet, R.F. (eds.). Managing Agricultural Greenhouse Gases, San Diego, USA: Academic Press. Zentner, R. P. (1995). EPIC model parameters for cereal, oilseed, and forage crops in the northern Great Plains region. Canadian Journal of Plant Science, 75(3), 679-688. https://doi.org/10.4141/cjps95-114 
890 Liu, J., Folberth, C., Yang, H., Röckström, J., Abbaspour, K., \& Zehnder, A. J. B. (2013). A

891 Global and Spatially Explicit Assessment of Climate Change Impacts on Crop Production

892 and Consumptive Water Use. PLOS ONE, 8(2), e57750.

$893 \quad$ https://doi.org/10.1371/journal.pone.0057750

894 Lobell, D. B., Cassman, K. G., \& Field, C. B. (2009). Crop Yield Gaps: Their Importance,

895 Magnitudes, and Causes. Annual Review of Environment and Resources, 34(1), 179-204.

$896 \quad$ https://doi.org/10.1146/annurev.environ.041008.093740

897 Meinshausen, N. (2006). Quantile Regression Forests. J. Mach. Learn. Res., 7, 983-999.

898 Mueller, N. D., Gerber, J. S., Johnston, M., Ray, D. K., Ramankutty, N., \& Foley, J. A. (2012).

899 Closing yield gaps through nutrient and water management. Nature, 490(7419), 254-257.

$900 \quad$ https://doi.org/10.1038/nature11420

901 Müller, C., \& Robertson, R. D. (2014). Projecting future crop productivity for global economic

902 modeling. Agricultural Economics, 45(1), 37-50. https://doi.org/10.1111/agec.12088

903 Müller, C., Elliott, J., Chryssanthacopoulos, J., Arneth, A., Balkovic, J., Ciais, P., ... Yang, H.

904 (2017). Global gridded crop model evaluation: benchmarking, skills, deficiencies and

905 implications. Geosci. Model Dev., 10(4), 1403-1422. https://doi.org/10.5194/gmd-10-

$906 \underline{1403-2017}$

907 Nash, J. E., \& Sutcliffe, J. V. (1970). River flow forecasting through conceptual models part I —

908 A discussion of principles. Journal of Hydrology, 10(3), 282-290.

$909 \quad$ https://doi.org/10.1016/0022-1694(70)90255-6 
910 Oyebamiji, O. K., Edwards, N. R., Holden, P. B., Garthwaite, P. H., Schaphoff, S., \& Gerten, D.

911 (2015). Emulating global climate change impacts on crop yields. Statistical Modelling,

912 15(6), 499-525. https://doi.org/10.1177/1471082X14568248

913 Peel, M. C., Finlayson, B. L., \& McMahon, T. A. (2007). Updated world map of the Köppen-

914 Geiger climate classification. Hydrol. Earth Syst. Sci., 11(5), 1633-1644.

915 https://doi.org/10.5194/hess-11-1633-2007

916 Portmann, F.T., Siebert, S., \& Döll, P. (2010). MIRCA2000 - global monthly irrigated and

917 rainfed crop areas around the year 2000: a new high-resolution dataset for agricultural

918 and hydrological modeling. Global Biogeochem. Cycles 24, GB1011,

919 https://doi.org/10.1029/2008GB003435

920 Pugh, T. A. M., Müller, C., Elliott, J., Deryng, D., Folberth, C., Olin, S., ... Arneth, A. (2016).

921 Climate analogues suggest limited potential for intensification of production on current

922 croplands under climate change. Nature Communications, 7, 12608.

923 https://doi.org/10.1038/ncomms12608

924 R Development Core Team (2008). R: A language and environment for statistical computing, $R$

925 Foundation for Statistical Computing. Vienna, Austria, Retrieved from https://www.R-

$926 \quad$ project.org.

927 Reidsma, P., Ewert, F., Boogaard, H., \& Diepen, K. van. (2009). Regional crop modelling in

928 Europe: The impact of climatic conditions and farm characteristics on maize yields.

929 Agricultural Systems, 100(1), 51-60. https://doi.org/10.1016/j.agsy.2008.12.009 
930 Rienecker, M. M., Suarez, M. J., Gelaro, R., Todling, R., Bacmeister, J., Liu, E., ... Woollen, J.

931 (2011). MERRA: NASA's Modern-Era Retrospective Analysis for Research and

932 Applications. Journal of Climate, 24(14), 3624-3648. https://doi.org/10.1175/JCLI-D-11-

$933 \underline{00015.1}$

934 Rosenzweig, C., Elliott, J., Deryng, D., Ruane, A. C., Müller, C., Arneth, A., ... Jones, J. W.

935 (2014). Assessing agricultural risks of climate change in the 21st century in a global

936 gridded crop model intercomparison. Proceedings of the National Academy of Sciences,

937 111(9), 3268-3273. https://doi.org/10.1073/pnas.1222463110

938 Rosenzweig, C., Ruane, A. C., Antle, J., Elliott, J., Ashfaq, M., Chatta, A. A., ... Wiebe, K.

939 (2018). Coordinating AgMIP data and models across global and regional scales for $1.5^{\circ} \mathrm{C}$

$940 \quad$ and $2.0^{\circ} \mathrm{C}$ assessments. Phil. Trans. R. Soc. A, 376(2119), 20160455.

$941 \quad$ https://doi.org/10.1098/rsta.2016.0455

942 Ruane, A. C., Goldberg, R., \& Chryssanthacopoulos, J. (2015). Climate forcing datasets for

943 agricultural modeling: Merged products for gap-filling and historical climate series

944 estimation. Agricultural and Forest Meteorology, 200, 233-248.

$945 \quad$ https://doi.org/10.1016/j.agrformet.2014.09.016

946 Ruane, A. C., Rosenzweig, C., Asseng, S., Boote, K. J., Elliott, J., Ewert, F., ... Thorburn, P. J.

947 (2017). An AgMIP framework for improved agricultural representation in integrated

948 assessment models. Environmental Research Letters, 12(12), 125003.

949 https://doi.org/10.1088/1748-9326/aa8da6 
950 Sacks, W. J., Deryng D., Foley J. A., \& Ramankutty N. (2010). Crop planting dates: an analysis 951 of global patterns. Global Ecology and Biogeography, 19(5), 607-620.

$952 \quad$ https://doi.org/10.1111/j.1466-8238.2010.00551.x

953 Schauberger, B., Archontoulis, S., Arneth, A., Balkovic, J., Ciais, P., Deryng, D., ... Frieler, K. 954 (2017). Consistent negative response of US crops to high temperatures in observations 955 and crop models. Nature Communications, 8, 13931.

$956 \quad$ https://doi.org/10.1038/ncomms13931

957 Sharpley, A.N., \& Williams, J.R. (1990). EPIC - Erosion/Productivity Impact Calculator: 1.

$958 \quad$ Model Documentation (US Department of Agriculture Technical Bulletin 1768).

959 Retrieved from http://agrilife.org/epicapex/files/2015/05/EpicModelDocumentation.pdf

960 SIAP (2018a). Avance de Siembras y Cosechas - Resumen nacional por estado. Servicio de 961 Información Agroalimentaria y Pesquera (SIAP). Retrieved from

$962 \quad$ https://www.gob.mx/siap

963 SIAP (2018b). Estadística de Producción Agrícola. Servicio de Información Agroalimentaria y 964 Pesquera (SIAP). Retrieved from http://infosiap.siap.gob.mx/gobmx/datosAbiertos.php

965 Skalský, R., Tarasovičová, Z., Balkovič, J., Schmid, E., Fuchs, M., Moltchanova, E.,

966 Kindermann, G., \& Scholtz, P. (2008). Geo-bene global database for biophysical

967 modelling v. 1.0. Concepts, methodologies and data: Retrieved from http://www.geo-

968 bene.eu/files/Deliverables/Geo-BeneGlbDb10\%28DataDescription\%29.pdf

969 Stockle, C. O., Williams, J. R., Rosenberg, N. J., \& Jones, C. A. (1992). A method for estimating

970 the direct and climatic effects of rising atmospheric carbon dioxide on growth and yield 
of crops: Part I-Modification of the EPIC model for climate change analysis. Agricultural Systems, 38(3), 225-238. https://doi.org/10.1016/0308-521X(92)90067-X

973 The H2O.ai team (2017). h2o: R Interface for H2O. R package version 3.14.0.3. Retreived from 974 https://CRAN.R-project.org/package=h2o

975 Toloşi, L., \& Lengauer, T. (2011). Classification with correlated features: unreliability of feature 976 ranking and solutions. Bioinformatics, 27(14), 1986-1994.

977 https://doi.org/10.1093/bioinformatics/btr300

978 Wang, T., Hamann, A., Spittlehouse, D., \& Carroll, C. (2016). Locally Downscaled and Spatially

979 Customizable Climate Data for Historical and Future Periods for North America. PLOS

980 ONE, 11(6), e0156720. https://doi.org/10.1371/journal.pone.0156720

981 Wickham, H. (2009). ggplot2: Elegant Graphics for Data Analysis. New York, USA: Springer.

982 Williams, J.R. (1995). The EPIC Model. In: Singh, V. P. (ed.). Computer Models of Watershed 983 Hydrology, Water Resources Publications.

984 Witten, I. H., Frank, E., Hall, M. A., \& Pal, C. J. (2016). Data Mining: Practical machine 985 learning tools and techniques. Burlington, USA: Morgan Kaufmann.

986 You, L., Wood-Sichra, U., Fritz, S., Guo, Z., See, L., \& Koo, J. (2017). Spatial Production 987 Allocation Model (SPAM) 2005 v3.2. March 6, 2018. Retrieved from 988 http://mapspam.info.

989 Zambrano-Bigiarini, M. (2014). hydroGOF: Goodness-of-fit functions for comparison of $990 \quad$ simulated and observed hydrological time series. $R$ package version $0.3-8$. Retrieved 991 from https://CRAN.R-project.org/package=hydroGOF 